\title{
Enhancement of Oxygen Transfer Rate Using Microencapsulated Silicone Oils as Oxygen Carriers
}

\author{
by \\ Ricky Leung, B. Eng \\ Department of Chemical Engineering \\ McGill University, Montreal
}

A thesis submitted to the Faculty of Graduate Studies and Research in partial fulfilment of the requirements for the degree of Master of Engineering.

(C) 1992 Ricky Leung

November 1992 


\section{ACKNOWLEDGEMENTS}

I would like to thank the following people for their support during the research and in the preparation of my thesis:

- Dr. Neufeld for his technical expertise, encouragement and guidance throughout the entire research period,

- Dr. Poncelet for his help, especially in the fluidized bed fermentation section, and also giving an opportunity to present my research in the "Bioencapsulation - Key to Bioindustry" Conference in France,

- the numerous co-workers in Dr. Neufeld's laboratory who helped me out, especially took samples for me during those long fermentation processes,

- J. Dumont and the staff in the machine shop for the equipment supply and helped building the fluidized bed reactor. 


\section{ABSTRACT}

Silicone oils were microencapsulated within polyamide(nylon)membranes cross-linked with polyethylenimine. Solubility of oxygen within the silicone oils, whether encapsulated or not, was approximately $6 \mathrm{mM}$, representing solubilities 20 fold higher than that of oxygen in water. Assuming that the bioreactor volume consists of 10 to $20 \%$ microencapsulated silicone oil, this represents an enhancement of the oxygen reservoir by a factor ranging from 4 to 7 . The use of $20 \%(\mathrm{v} / \mathrm{v})$ microcapsule dispersions also enabled a 4 to 5 times increase of volumetric oxygen transfer coefficient $\left(k_{L^{a}}\right)$, calculated on a per-litre aqueous phase basis, with or without the presence of cells. The improvement in oxygen transfer rates was due to the greatly increased specific surface area in comparison to conventional bubble aeration. These oxygen transfer enhancements were directly translatable into enhancements in overall productivity in a culture of Gluconobacter suboxydans (ATCC 621). The production rate of dihydroxyacetone was increased from 1.5 to $9 \mathrm{mM} \mathrm{DHA} / \mathrm{hr}$ with the introduction of $20 \%$ of microcapsules in a batch fermentation and also from 6 to $8 \mathrm{mM} \mathrm{DIIA} / \mathrm{hr}$ in a fluidized bed fermentation. Thus, the oygen permeable polymeric membrane coating the silicone oils as oxygen carrier should reduce the toxic or inhibitory effects previously observed in other oxygen carriers during use with live cells while providıng an efficient alternative to bioreactor oxygenation with shear sensitive cell systems, or in fermentations with high oxygen requirements. 


\section{RÉSUMÉ}

Les huiles de silicones ont ete microencapsuler dans des membranes de polyamide crosslinked avec du poiyethylenimine. La solubilite de l'oxygene dans les huiles de silicone encapsuler ou pas etait approximativement $6 \mathrm{mM}$, donnant une solubilite de 20 fois plus que dansl'eau. En assument que le volume du bio-reacteur consiste de 10 a $20 \%$ d'huiles de silicone microencapsuler, ce qui donnerait une augmentation des reserves d'oxygene de 4 a 7 fois la normal. L'utilization de dispersions microencapsuler de $20 \%(\mathrm{v} / \mathrm{v})$ a permis d'avantage un augmentation de 4 a 5 fois du coefficient de transfer volumetric d'oxygene $\left(k_{\mathrm{L}} \mathrm{a}\right)$ calculer pour un volume d'un litre de phase aqueuse avec ou sans la presences d': cellules. L'amilioration du taux de transfer d'oxygene etait due a la grande augmentation de la superficie specifique comparer a la methode conventionelle d'airation directe. Ces ameliorations en taux de transfer d'oxygene se transmettent airectement en une amelioration de productivite dans une culture de Gluconobacter oxydans (ATCC 621) Il serait suggerer que le revetement de membrane polymeric des huiles de silicone agisant comme transporteur d'oxygene devrait reduire les effets toxic ou inhibitoire observer auparavant en utilisant des cellules vivantes donnant un alternative efficase a l'oxigenation due bio-reacteur avec des systemes cellulaires sensible, ou dans des fermentations requerant de grands nivaux d'oxygene. 


\section{TABLE OF CONTENTS}

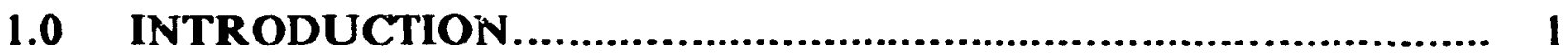

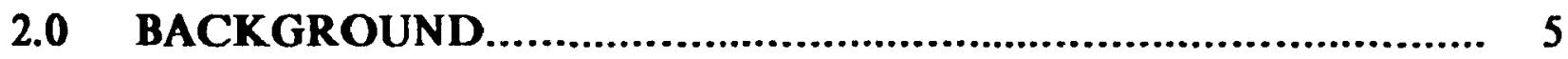

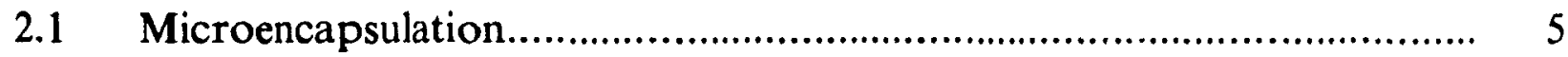

2.2 Oxygen Transfer Rate Measurement ..................................................... 6

2.2.1 $\mathrm{k}_{\mathrm{L}} \mathrm{a}$ Measurement Methods........................................................... 9

2.3 Background of the Micrn-organism................................................ 11

3.0 MATERIALS AND METHODS........................................ 13

3.1 Microencapsulation of Silicone Oils................................................ 13

3.2 Microcapsule Size Distribution Analysis............................................. 15

3.3 Microcapsule Physical Properties........................................................ 15

$3.4 \quad$ Oxygen Solubility and Partition..................................................... 15

3.4.1 Modelling of Oxygen Solubility and Partition.................................. 17

3.5 Oxygen Transfer Determination...................................................... 20

3.5.1 $\mathrm{k}_{\mathrm{L}}$ a Measurements Using Dynamic Methods................................. 20

3.5.2 Oxygen Probe Response.............................................................. 22

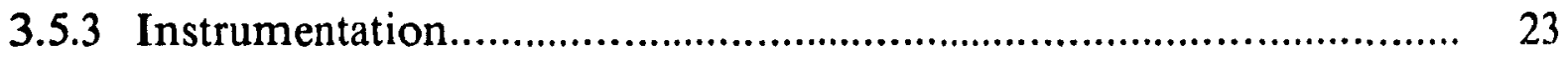

3.5.4 Experimental Design................................................................ 24

3.5.4.1 Agitation-Aeration System..................................................... 24

3.5.4.2 Non-aeration System............................................................ 24

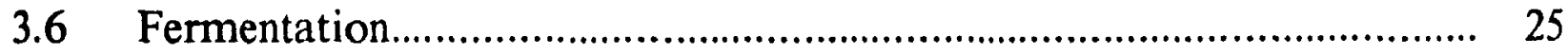

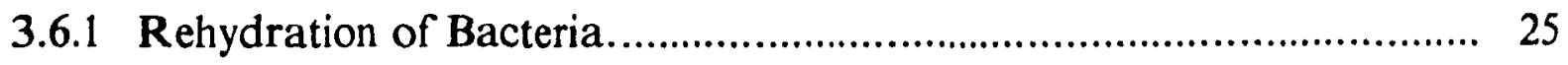

3.6.2 Cultivation of Bacteria.............................................................. 26 
3.6.3 Estimation of Biomass Concentration........................................... 27

3.6.4 Quantification of Dihydroxyacetone.......................................... 27

3.6.5 Batch Fermentation................................................................. 28

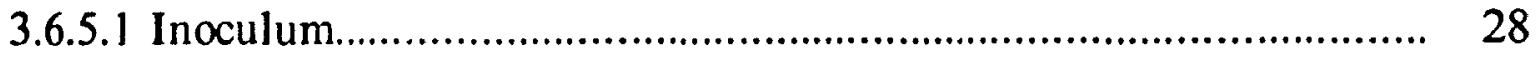

3.6.5.2 Batch Fermentation Conditions................................................ 28

3.6.6 Fluidized Bed Fermentation......................................................... 29

3.6.6.1 Immobilzation of Cells............................................................. 29

3.6.6.2 Experimental Set-up............................................................. 30

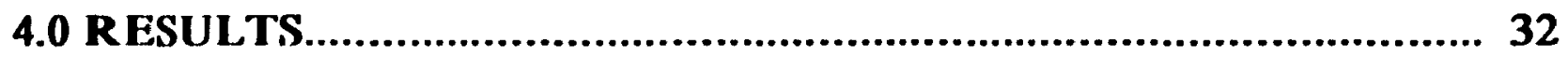

4.1 Preparation of Microcapsules.......................................................... 32

4.2 Microcapsule Size Distribution........................................................ 35

4.3 Oxygen Solubility in Silicone Oils and other Solvents........................... 38

4.4 Mass Transfer of Oxygen from Microencapsulated Oxygen Carriers......... 41

4.4.1 Oxygen Electrode Response Time................................................... 36

4.4.2 Oxygen Electrode Dynamics........................................................ 42

4.4.3 $\mathrm{k}_{\mathrm{L}}$ a Measurements without Cells................................................... 45

4.4.3.1 Non-aeration System............................................................ 45

4.4.3.2 Bubble Aerated System ......................................................... 46

4.4.4 $\mathrm{k}_{\mathrm{L}} \mathrm{a}$ Measurements with Cells..................................................... 49

4.5 Fermentation Results................................................................. 50

4.5.1 Flask Fermentation.............................................................. 50

4.5.2 Batch Fermentation............................................................... 51

4.5.3 Fluidized Bed Fermentation.......................................................... 54 


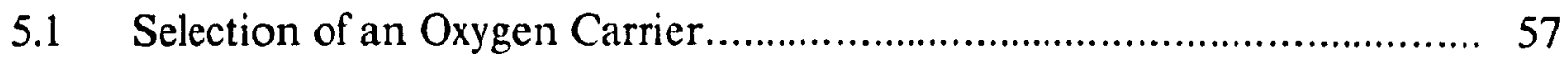

5.2 Microencapsulation of Oxygen Carrier.............................................. 59

5.3 Oxygenation Capacity by Microencapsulated Silicone Oils.................... 60

5.3.1 Oxygenation Capacity by Microencapsulated Silicone Oils

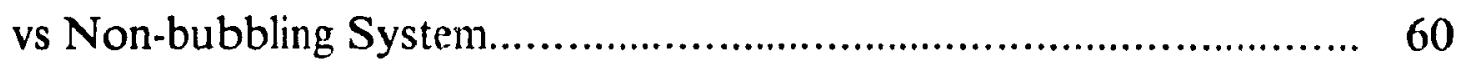

5.3.2 Oxygenation Capacity by Microencapsulated Silicone Oils

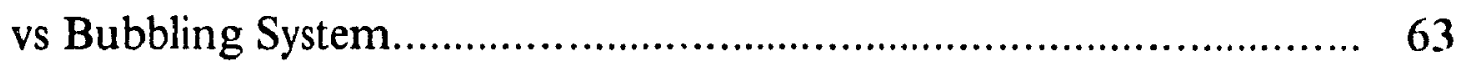

5.3.3 Oxygenation Capacity by Microencapsulated Silicone Oils

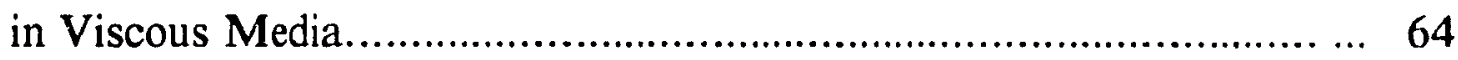

5.4 Oxygen Transfer Rate Enhancement using Microencapsulated

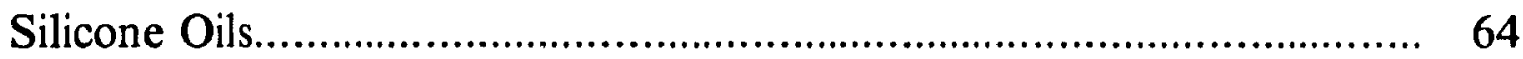

5.5 Comparison of Oxygen Transfer Performance between Microencapsulated Silicone Oils and other Oxygen Carriers.................. 66

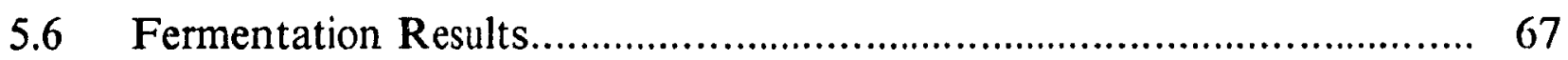

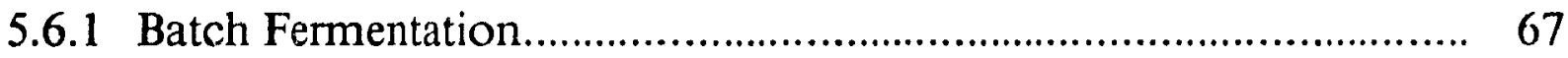

5.6.2 Fluidized Bed Fermentation..................................................... 69

6.0 CONCLUSIONS........................................................ 71

$7.0 \quad$ NOMENCLATURE................................................... 72

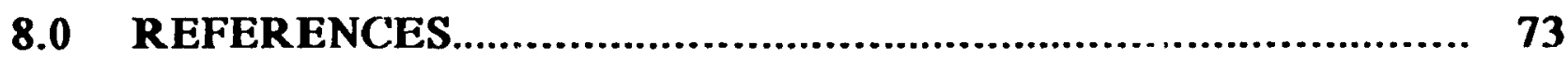




\subsection{INTRODUCTION}

In industrial fermentation technology, the rate of oxygen supply to submerged ninicrobial cells has long been recognized as a major limiting factor. This occurs when the oxygen supply rate to the aqueous phase cannot match the overall oxygen consumption rate under equilibrium conditions causing the amount of dissolved oxygen to fall below the critical concentration needed for the microorganisms to maintain metabolic activities. In conventional bubble aerated bioreactors, low oxygen solubility $\left(0.28 \mathrm{mM}\right.$ at $\left.20^{\circ} \mathrm{C}\right)$ combined with slow oxygen transfer rates often results in poor growth of microbial cells or poor yield of fermentation products.

Various techniques are used in conventional aerobic fermentation technology to improve the rate of oxygen transfer from the gas phase into the liquid medium, such as, increasing the agitation speed and the amount of aeration, raising the partial pressure of oxygen in the gas phase, or improving the shape of the fermentation vessel. These tr. hniques are of ten costly and vigorous mixing creates high shear stresses incompatible with the culture of fragile cells.

Other methods have been reported to achieve good oxygen supply to microbial cells. One approdch was to generate oxygen in situ using a hydrogen peroxide /catalase system $^{36,37}$, or by adding hydrogen peroxide to the medium and using an organism with a high natural catalase activity ${ }^{22}$. However, hydrogen peroxide is toxic and results in 
a reduction in growth at high cell densities ${ }^{3}$.

Another approach was to replace oxygen by another electron acceptor such as p-benzoquinone ${ }^{45}$. The reaction rate was four times higher compared to when oxygen was used. However, the drawback of this technique is that not all organ!sms are able to use p-benzoquinone as an oxygen substitute and toxic effects were observed over the long term. Adlercreutz et al. observed that productivity decreased from 60 to 10 mmol/h.g in a 8-day period when using Gluconobacter oxydans and p-benzoquinone for the oxidation of glycerol to dihydroxyacetone $\mathrm{A}^{4}$.

A biological approach has also been reported involving the generation of oxygen in situ. Adlercreutz et al. repurted that Gluconobacter oxydans, co-immobilized with the oxygen-producing algae, Chlorella pyrenoidosa, is 5.4 times more effective in the production of dihydroxyacetone than when in pure culture. However, the oxygen production is limited and co-immobilization may cause inhibition or competition for the substrate ${ }^{2}$.

Yet another novel method reported is cloning and expression of hemoglobin into the host system for enhancing the utilization of oxygen. However, this technique can only be applied to a limited number of biological systems.

Finally, oxygen supply may be enhanced by the introduction of oxygen carriers, compounds with high oxygen solubility, into the aqueous medium. Oxygen carriers 
include hemoglobin ${ }^{3}$, perfluorocarbon chemicals (PFC's) ${ }^{13,19}$, and low viscosity silicone oils $^{11,25}$. Hemoglobin has limited application since it is not stable in fermentation medium. It is oxidized to met-hemoglobin concomitant with a loss in oxygen absorption capacity ${ }^{3}$. Moreover, the growth rate of $E$. coli is inhibited by emulsified perfluorocarbons and the emulsifiers as dispersants. Chandler et al. ${ }^{10}$ showed that emulsion from proprietary formulation, Fluosol-DA (20\%), and also a combination of the Pluronic F-68 surfactant and yolk phospholipid emulsion stabilizer inhibited the growth of $E$. coli. Yeast growth is also inhibited by Fluosol stem emulsion and pluronic alone. Furthermore, electron microscopic examination of yeast cell thin sections, following culture in perfluorodecalin emulsion revealed cytoplasmic vacuolation and other ultrastructural perturbations ${ }^{9}$. Lowe $e t$ al. ${ }^{28}$ showed that some PFC's led to inhibition of growth and other negative effects to many mammalian cells. Junker and Wang ${ }^{45}$ also found that the initial cell density from a uniform inoculum decreased at high PFC volume fractions due to increased cell adsorption at the water-PFC interface.

Silicone oils have been used to supply oxygen to liquid medium. Chibata et al. ${ }^{11}$ observed that silicone oil has at least twice the oxygen solubility of perfluorocarbon liquids. For example, oxygen solubility (at $25^{\circ} \mathrm{C}$ ) for perfluorotributylamine (FC-43) is $39 \mathrm{ml}$ of oxygen dissolved in $100 \mathrm{ml}$ liq., and for perfluoro-1-methyldecaline is $43 \mathrm{ml}$ $100 \mathrm{ml}$ liq.; whereas for silicone oil (Dow Corning 200 fluid - $1 \mathrm{cs}$ ), the oxygen solubility 
is $100 \mathrm{ml} / 100 \mathrm{ml}$ liq. $\left(25^{\circ} \mathrm{C}\right)$. Moreover, Leonhardt et al. reported that the L-amino acid oxidase activity of immobilized cells was increased by a factor of four in the presence of silicone emulsion ${ }^{24}$.

Oxygen carriers seem to enhance the fermentation performance. However, in most cases, after prolonged contact with oxygen carriers, the fermentation system became unstable due to loss of activity of the microbial cells ${ }^{10}$, toxicity of the oxygen carriers $^{28}$, or the increased cell adsorption at the water-oil interface ${ }^{45}$.

Previous problems with the use of oxygen carriers immiscible in the aqueous phase, led to the notion of encapsulating the oxygen carriers within ultra-thin oxygenpermeable membranes such as polyamide films, eliminating direct contact between the liquid medium and the oxygen carriers. Pcrcelet $e t$ al. reported that silicone oils were successfully encapsulated by semi-permeable nylon membranes, and under certain conditions, the oxygen reservoir in water containing 10 to $20 \%$ microcapsules was enhanced by a factor ranging from four to seven ${ }^{32}$.

The aim of this project was to examine the enhancement of oxygen transfer due to microencapsulated silicone oils during aerobic fermentation. Determination of oxygen solubility and transfer rate from microcapsules, and evaluation of fermentation productivity using microencapsulated oxygen carriers in different types of fermentation systems are described. 


\subsection{BACKGROUND}

\subsection{Microencapsulation}

Microencapsulation is an immobilization technique whereby small discrete solid particles or liquid droplets are enclosed within an intact shell of natural or synthetic polymers. The microcapsules are typically spherical with diameters ranging from $5 \mu \mathrm{m}$ to $1000 \mu \mathrm{m}$. However, this range may be extended from $1 \mu \mathrm{m}$ up to $5000 \mu \mathrm{m}$ in diameter $^{24}$.

The concept of microencapsulation originated in the 1960's. Early work of microencapsulation involved the formation of impermeable membranes. One of the first industrial uses was the coating of paper with encapsulated ink to produce carbonless copy paper in 1953. Other applications include "microfragrance" for advertising and publicity, controlling the rate of drug release in the pharmaceutical industry, and the introduction of flavors and aromas in the food industry. After the development of semi-permeable membranes, applications were developed in medicine as detoxicants or artificial cells, in agriculture for slow release of fertilizers, and in the textile and printing industry as dye precursors. 


\subsection{Oxygen Transfer Rate Measurement}

In order to maintain metabolic activities of microbial cells, the oxygen supply rate must match the overall oxygen consumption rate under equilibrium conditions. Oxygen supply requires transferring oxygen through gas-liquid contacting, followed by transporting dissolved oxygen to respiring microorganisms. With adequate agitation, the gas-to-liquid oxygen transfer resistance often controls the overall oxygen supply rate in fermentations without microbial aggregates or pellets. The oxygen transfer rate, OTR, is usually expressed as follows:

$$
\text { OTR }=k_{L} a\left(C^{*}-C_{L}\right)
$$

where

$$
\begin{aligned}
& k_{L}=\text { liquid phase oxygen transfer coefficient, } \mathrm{cm} / \mathrm{s} \\
& a=\text { interfacial area per unit volume of dispersion, } \mathrm{cm}^{2} / \mathrm{cm}^{3} \\
& C^{*}=\text { saturation concentration of dissolved oxygen at bubble surface, mol/L } \\
& C_{L}=\text { bulk concentration of dissolved oxygen, } \mathrm{mol} / \mathrm{L}
\end{aligned}
$$


For perfectly mixed vessels, the saturation concentration, $\mathrm{C}^{*}$, is in equilibrium with the oxygen partial pressure of the exhaust gas, i.e.,

$$
\mathbf{C}^{*}=\mathbf{H} p_{\mathrm{o}}
$$

where $\quad p_{\mathrm{o}}=$ oxygen partial pressure of the exhaust gas,

$$
H=\text { Henry Law constant of the fermentation medium (mol/l-atm). }
$$

The Henry Law constant can be either measured directly or calculated on the basis of chemical composition of the fluid. Similarly, the bulk concentration, $C_{L}$, corresponds to $p_{1}$, the average oxygen partial pressure in the fermenter:

$$
\mathrm{C}_{\mathrm{L}}=\mathrm{H} p_{1}
$$

In practice, $p_{1}$ can be measured directly with a dissolved oxygen probe. Thus, equation (1) can be transformed to:

$$
\operatorname{OTR}=\mathrm{k}_{\mathrm{L}} \mathrm{a} \mathbf{H}\left(p_{\mathrm{o}}-p_{1}\right)
$$


In theory, the maximum theoretical driving force is achieved when $p_{1}=0$,

$$
\operatorname{OTR}=\mathrm{k}_{\mathrm{L}} \mathrm{a} \mathrm{H}\left(p_{\mathrm{o}}\right)
$$

Thus, the oxygen supply rate is strongly influenced by oxygen solubility in the fermentation medium $\left(C_{L}<0.3 \mathrm{mM}\right.$ or $10 \mathrm{mg} / \mathrm{L}$ for typical fermentation medium).

Both $\mathrm{k}_{\mathrm{L}}$ and a can be affected in several ways. Among the most important variables are power consumption, gas superficial velocity, and liquid phase properties such as ionic strength, surface tension and viscosity.

In fermentation, the oxygen balance can be described by eq. (1) with the addition of one term to account for the oxygen consumption by the culture:

$$
\mathrm{dC}_{\mathrm{L}} / \mathrm{dt}=\mathrm{k}_{\mathrm{L}} \mathrm{a}\left(\mathrm{C}^{*}-\mathrm{C}_{\mathrm{L}}\right)-\mathrm{Q}_{\mathrm{O} 2} \mathrm{X}
$$

where $\quad Q_{\mathrm{O} 2}=$ specific rate of Oxygen consumption (mole $/ \mathrm{g} / \mathrm{hr}$ )

$$
\mathrm{X}=\text { biomass concentration }(\mathrm{g} / \mathrm{l})
$$


$k_{L} a$ can be obtained from equation (6) either in dynamic or steady-state conditions. In the latter case, $\mathrm{dC}_{\mathrm{L}} / \mathrm{dt}=0$, and

$$
\mathbf{k}_{\mathrm{L}} \mathrm{a}=\mathrm{Q}_{\mathrm{O} 2} \mathrm{X} /\left(\mathrm{C}^{*}-\mathrm{C}_{\mathrm{L}}\right)
$$

Another method to determine $\mathrm{k}_{\mathrm{L}} \mathrm{a}$ is in the unsteady state. Rearranging equation

(6) gives:

$$
C_{L}=\left(-1 / k_{L} a\right)\left(d C_{L} / d t+Q_{O 2} X\right)+C^{*}
$$

A plot of $C_{L}$ vs $d C_{L} / d t+Q_{O 2} X$ will have a slope of $-1 / k_{L}$ a and $y$-intercept of $C^{*}$.

\subsection{1 $\mathrm{k}_{\mathrm{L}}$ a Measurement Methods}

The $\mathrm{k}_{\mathrm{L}}$ a can be measured by various methods:

Direct Measurement. The most reliable method available simply measures the oxygen absorption directly. Instrumentation for this technique includes a gaseous oxygen analyzer, flow meters, pressure gauges and temperature 
measuring devices. A material balance around the system will yield the oxygen transfer rate.

Dynamic Method. This method makes use of non-steady state oxygen transfer conditions, where $\mathrm{dC}_{\mathrm{L}} / \mathrm{dt} \neq 0$. The underlying principle is that after a given liquid has been deoxygenated by purging with an inert gas (e.g. nitrogen), the re-oxygenation profile is monitored by an oxygen electrode probe following reintroduction of air.

Sodium Sulphite Oxidation. This technique is based on the oxidation of sodium sulphite in the presence of a catalyst:

$$
\mathrm{Na}_{2} \mathrm{SO}_{3}+0.5 \mathrm{O}_{2}{ }^{2+} \text { or } \mathrm{Cu}^{2+}
$$

The reaction is very fast as compared with the physical dissolution of oxygen, and therefore $C_{L}=0$ as oxygen is reduced as soon as it transfers into solution. The rate of $\mathrm{SO}_{3}^{2-}$ oxidation, measured by withdrawing samples at various times and titrating the unreacted $\mathrm{SO}_{3}{ }^{2-}$ with iodine, is assumed to represent the rate of oxygen transfer. The major limitation to this technique is that it cannot simulate an actual fermentation in the absence of cells. 


\subsection{Background of the Microorganism}

The strain, Gluconobacter oxydans subsp. suboxydans, was obtained from the American Type Culture Collection (ATCC 621).

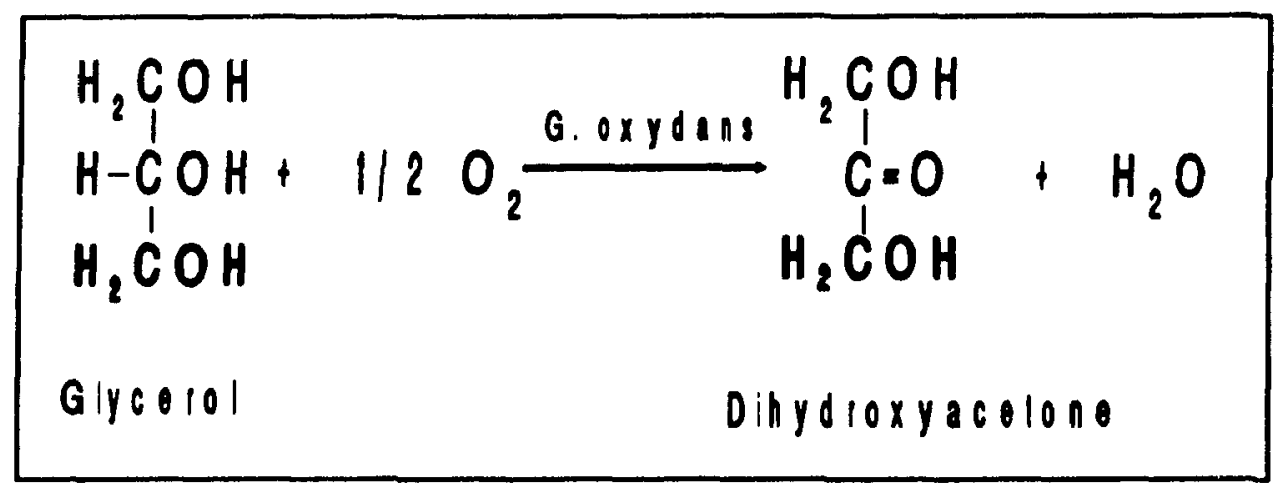

Figure 1. Oxidation of Glycerol to Dihydroxyacetone (DHA)

Bioconversion of glycerol to dihydroxyacetone is used for industrial DHA production for pharmaceutical purposes and chemical synthesis. G. suboxydans has two pathways forming DHA-3-phosphate from glycerol ${ }^{8}$ :

1) direct oxidation of glycerol to DHA by a NAD-independent membrane-linked glycerol dehydrogenase, which is optimal at pH 6.0.

The DHA can be eventually phosphorylated by a kirase; 
2) conversion of glycerol into glycerol-3-phosphate by a kinase and then oxidation to DHA-3-phosphate by a NAD-dependent dehydrogenase. The optimal pH of this reaction is 8.5 .

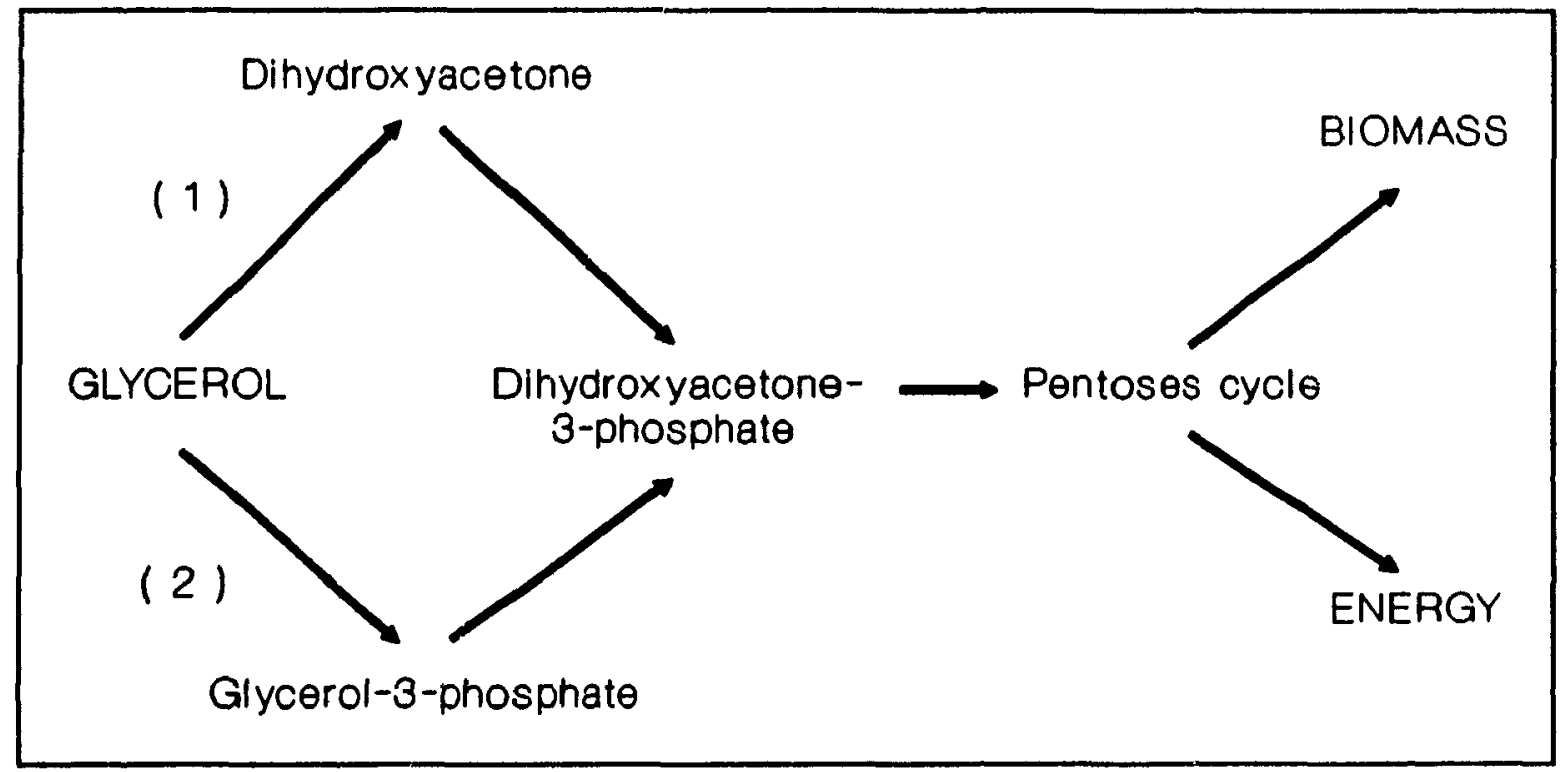

Figure 2. Metabolism of glycerol in G.oxydans. (1) Principal pathway at pH 6 leading to DHA accumulation in the culture batch. (2) Pathway leading to biomass synthesis from glycerol as source of carbon and energy.

The DHA-3-P can be used later for biomass and energy synthesis by the pentose phosphate pathway. DHA is usually produced by the non-phosphorylation oxidative pathway more quickly than it is consumed causing an accumulation of DHA in the fermentation medium. 


\subsection{MATERIALS AND METHODS}

\subsection{Microencapsulation of Silicone Oils}

Nylon membranes were formed by interfacial polymerization around an emulsified organic phase containing silicone oils (Dow Corning 200 Fluid -- $10 \mathrm{cs}$ ). The silicone oil containing $45 \mathrm{mM}$ sebacoyl chloride (Aldrich) was dispersed within an aqueous phase with the aid of $2 \%(\mathrm{v} / \mathrm{v}$ ) emulsifier (Dow Corning 190 Fluid), and $0.2 \mathrm{M}$ sodium bicarbonate as a buffer. Emulsification was performed in a $250 \mathrm{ml}$ vessel (internal diameter $55 \mathrm{~mm}$ ) with four $5 \mathrm{~mm}$ baffles using a $70 \mathrm{~mm}$ long sheet-lattice type impeller for mixing. The emulsion was mixed at $450 \mathrm{rpm}$ for 2 mins. Polymerization was initiated at the droplet interface by the addition of a diamine solution which consists of $0.6 \mathrm{M}$ 1,6-hexanediamine, and $2 \%(\mathrm{w} / \mathrm{v})$ polyethyleneimine tocross-link the membrane. The $\mathrm{pH}$ of the diamine solution was adjusted to 10.0 by addition of $1 \mathrm{~N}$ $\mathrm{HCl}$ before adding to the mixture. The volume of organic, aqueous and amine phase were 20,80 and $20 \mathrm{ml}$ (ratio 1:4:1) respectively. After 3 mins reaction time, the microcapsules were centrifuged, washed with distilled water, filtered, and suspended in distilled water for storage.

A simplified procedure is shown in figure 3. 


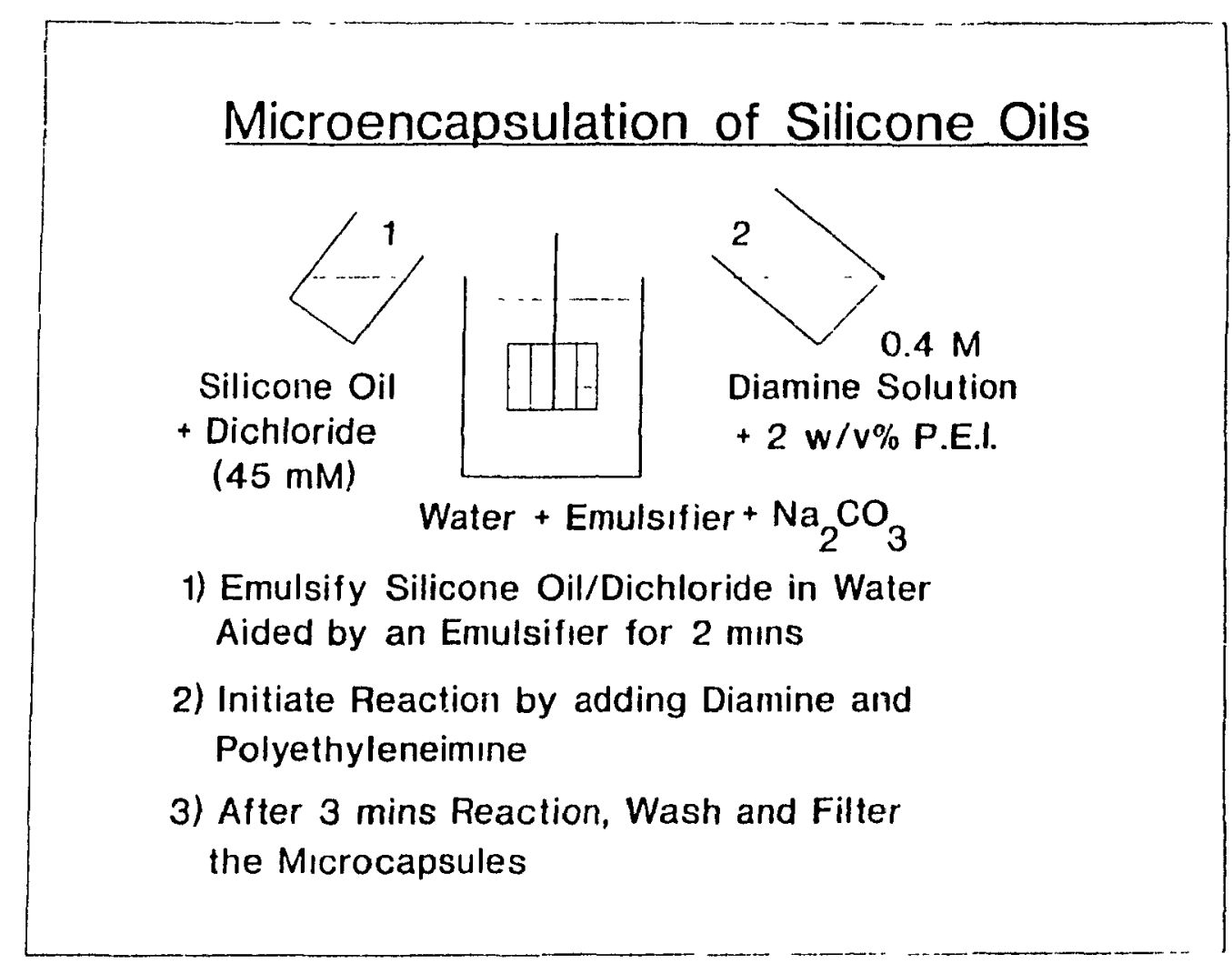

Figure 3. Procedure for Mic-oencapsulation of Silicone oils

Emulsification was carried out in a $250 \mathrm{ml}$ vessel ( $55 \mathrm{~mm}$ internal diameter) for small scale microencapsulation and a 2-litre vessel for larger quantities. The volume ratio of organic, aqueous and amine phase was 1:4:1. The emulsification time, reaction time and the rotational speed of the impeller were the same for both vessels. 


\subsection{Microcapsule Size Distribution Analysis}

Mean diameter and size distribution of the silicone oil microcapsules were determined with a Malvern Sizer 2600Lc(Malvern Instruments, England). The particle analyzer determined the volume distribution of the microcapsules and calculated an average size based on a log normal distribution. The arithmetic standard deviation was calculated from diameters at 16 and $84 \%$ of the cumulative distribution curves $\left[\sigma_{a}=\left(d_{84 \%}-d_{16 \%}\right)\right]$.

\subsection{Microcapsule Physical Properties}

Microcapsules were evaluated microscopically to evaluate sphericity, fraction of broken microcapsules and membrane strength. The membrane strength was evaluated qualitatively by compression to rupture with micromanipulators. Microcapsules were classified as very good $(+++)$, good $(++)$, satisfactory $(+)$ and unsatisfactory $(-)$ based on the ease of rupture.

\subsection{Oxygen Solubility and Partition}

The reactor used for solubility measurements consisted of a closed cylindrical polycarbonate vessel $(380 \mathrm{ml})$. An oxygen probe (YSI model 5739$)$ was fitted through 
a sealed port in the lid and reactants were injected through a second sealed port as illustrated in figure 4.

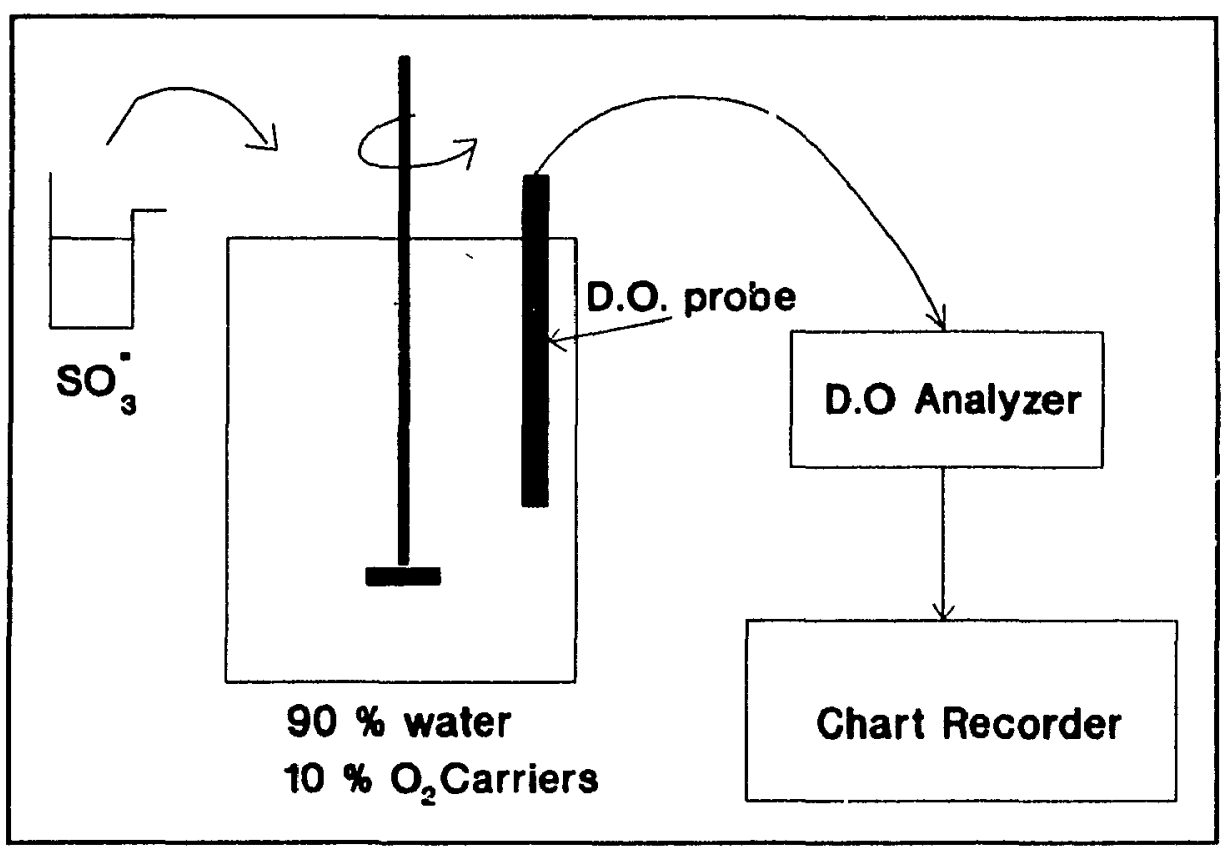

Figure 4. Oxygen Solubility and Partition Mcasurement

The oxygen solubility of silicone oil was determined in a two phase mixture of silicone/water (1/9 volume ratio). The probe was adjusted to measure oxygen tension in the aqueous phase with the two-phase mixture filling the entire volume of the reactor. After equilibration with air, sodium sulphite was added to the aqueous phase as an oxygen sink together with $0.1 \mathrm{mM}$ cobalt sulphate catalyst. The concentration of oxygen in the water phase was recorded at equilibrium following incremental additions of sulphite. Solubility and partitioning of oxygen was computed as described below. 
A concentrated sulphite solution was prepared just prior to use to minimize air oxidation. In all experiments, the volume of sulphite solution added was less than $0.1 \%$ of the reactor volume and its effect on the suspension volume was neglected. The polymeric microcapsule membranes contain a number of amine groups and behave like a base. Thus, the suspended microcapsules in distilled water were neutralized to ensure rapid oxidation of sulphite.

A similar procedure was followed to determine the oxygen solubility of microencapsulated silicone within water suspension (1/9 volume ratio). The volume of microcapsules was determined from the mass assuming a similar density to silicone oil.

\subsubsection{Modelling of Oxygen Solubility and Partition}

Sulphite is oxidized by oxygen according to:

$$
2 \mathrm{Na}_{2} \mathrm{SO}_{3}+\mathrm{O}_{2} \stackrel{\mathrm{Co}^{2 \cdot}}{\cdots-\cdots>>\mathrm{Na}_{2} \mathrm{SO}_{4}}
$$

The sulphite oxidized, $\mathbf{S}$, expressed in equivalent mol of oxygen reduced, is given by:

$$
\mathrm{S}=1 / 2\left[\mathrm{SO}_{3}{ }^{2}\right] \mathrm{V}_{\mathrm{s}}
$$


where $\mathrm{V}_{\mathrm{s}}$ is the volume of sulphite added. The mass balance of oxygen before and after addition of sulphite may be written:

$$
\left\{\left[\mathrm{O}_{2}\right]_{\mathrm{c}} \mathbf{V}_{\mathrm{c}}+\left[\mathrm{O}_{2}\right]_{\mathrm{w}} \mathbf{V}_{\mathrm{w}}\right\}_{1}=\left\{\left[\mathrm{O}_{2}\right]_{\mathrm{c}} \mathbf{V}_{\mathrm{c}}+\left[\mathrm{O}_{2}\right]_{\mathrm{w}} \mathbf{V}_{\mathrm{w}}\right\}_{\mathrm{f}}+\mathrm{S}
$$

where subscript $\mathbf{w}$ and $c$ refer to the water and the oxygen organic carrier phase respectively, and $i$ and $f$ drine initial and final state. Assuming a constant concentration ratio of oxygen between the water and organic phases, the partition constant, $\mathbf{K}$, is defined by:

$$
\mathrm{K}=\left\{\left[\mathrm{O}_{2}\right]_{\mathrm{c}} /\left[\mathrm{O}_{2}\right]_{\mathrm{w}}\right\}_{\text {al cquulbrium }}
$$

Combining equations (10) and (11):

$$
\left[O_{2}\right]_{w 1}\left(K V_{2}+V_{w}\right)=\left[O_{2}\right]_{w f}\left(K V_{c}+V_{w}\right)+S
$$

and by grouping oxygen terms $\left(\Delta\left[\mathrm{O}_{2}\right]_{\mathrm{w}}=\left[\mathrm{O}_{2}\right]_{\mathrm{wi}}-\left[\mathrm{O}_{2}\right]_{\mathrm{wf}}\right)$ :

$$
\Delta\left[\mathrm{O}_{2}\right]_{\mathrm{w}}\left(\mathrm{K} \mathrm{V}_{\mathrm{c}}+\mathrm{V}_{\mathrm{w}}\right)=\mathrm{S}
$$


The oxygen partition constant may be computed using equation (13), from the decrease in oxygen concentration, $\Delta\left[\mathrm{O}_{2}\right]_{w}$ following the addition of sulphite, $S$. For greater accuracy, the oxygen concentration, $\left[\mathrm{O}_{2}\right]_{w}$, was plotted as a function of the added sulphite, $S$. The slope, $m$, is equal to $\mathrm{KV}_{\mathrm{c}}+\mathrm{V}_{\mathrm{w}}$ and the partition constant is then calculated by:

$$
K=\left(m-V_{w}\right) / V_{c}
$$

Expressing the oxygen solubility as a partition constant is useful because it is insensitive to temperature and oxygen pressure. Knowing the oxygen solubility in water, the corresponding solubility in the oxygen carrier may be computed with Equation (11). Dividing the solubility by the oxygen pressure leads to the Henry's constant, another method of defining oxygen solubility independently of the oxygen pressure. 


\subsection{Oxygen Transfer Determination}

\subsection{1 $\mathrm{k}_{\mathrm{L}}$ a Measurements Using Dynamic Methods}

In this study, the dynamic method was used. This method makes use of the non-steady state oxygen transfer conditions, where $\mathrm{dC}_{\mathrm{L}} / \mathrm{dt} \neq 0$. After the given liquid had been deoxygenated, the dissolved oxygen concentration profile was monitored by means of an oxygen electrode following the re-introduction of air. The oxygen transfer coefficient was calculated with the aid of an appropriate mathematical model.

The removal of dissolved oxygen in the model system, i.e. without respiring microorganisms, required sparging with an oxygen-free gas, e.g. nitrogen gas, while in an active culture it was sufficient to discontinue the oxygen supply by stopping the aeration. When the desired agitation-aeration conditions were resumed, the oxygen concentration, $\mathrm{C}_{\mathrm{L}}$, started increasing at a rate,

$$
\mathrm{dC}_{\mathrm{L}} / \mathrm{dt}=\mathrm{k}_{\mathrm{L}} \mathrm{a}\left(\mathrm{C}^{\cdot}-\mathrm{C}_{\mathrm{L}}\right)-\mathrm{Q}_{\mathrm{O} 2} \mathrm{X}
$$

where

$$
\begin{aligned}
& C_{L}=\text { D.O. concentration at bulk liquid } \\
& C^{*}=\text { D.O. concentration in equilibrium with gas phase } \\
& Q_{\mathrm{O} 2} X=\text { Oxygen uptake rate of microorganisms. }
\end{aligned}
$$


During the aeration phase, $C_{L}$ increased with time until a steady state $C^{\circ}$ was reached. The above equation could be rearranged as:

$$
C_{L}=C^{*}-\left(1 / k_{L} a\right)\left(d C_{L} / d t+Q_{O 2} X\right)
$$

from which the $\mathrm{k}_{\mathrm{L}}$ a value was determined from the slope of D.O. concentration $\left(C_{L}\right)$ in function of $\left(\mathrm{dC}_{\mathrm{L}} / \mathrm{dt}+\mathrm{Q}_{\mathrm{O} 2}\right)$.

In the model system with no oxygen consumption, the last term of eq. (6) became zero. After integration in the range $C_{L 0}$ to $C_{L}$ and $t_{0}$ to $t$ using the assumption of constant $k_{L} a$ and $C^{*}$ yielded:

$$
k_{L} a=\left[1 /\left(t-t_{0}\right)\right] \ln \left[\left(C^{*}-C_{10}\right) /\left(C^{*}-C_{L}\right)\right]
$$

where $C_{L 0}=D \cdot O$. concentration at $t=0$.

Plotting the argument of the logarithm versus time on semi-log paper allowed the evaluation of $k_{L} a$ as the slope of the fitted straight line. 
However, the accuracy of the dynamic method may be influenced by the delayed response of the oxygen electrode signal due to oxygen diffusion through the membrane ${ }^{38}$.

\subsubsection{Oxygen Probe Response}

When using the dynamic $\mathrm{k}_{\mathrm{L}}$ a measurement, it is necessary to ensure that it is the response of the system that is being measured and not that of the dissolved oxygen probe. Thus, the probe gives the correct concentration when the probe response is much faster than the process response. This occurs when the time constant of the probe is much less than the time constant of the process, i.e. $T_{p} \ll$ $\left(1 / \mathrm{k}_{\mathrm{L}} \mathrm{a}\right)$

The method used to determine response time of the probe was to utilize two vessels, one with air saturated, and the other with nitrogen saturated water. After the probe had reached a stable reading in one vessel, it was quickly transferred to the other and the dynamic response was monitored until it reached a new steady state. The time constant of the probe was determined as the time to reach $63.2 \%$ of the new steady state value. 


\subsubsection{Instrumentation}

All $k_{L} a$ measurements were performed in a 2-litre glass bench-top fermenter. The working volume was 1 to 1.5 litres at ambient pressure. The reactor has an inner diameter of $15 \mathrm{~cm}$, a height of $30 \mathrm{~cm}$ and was equipped with a vertical agitator shaft turning three (or two) sets of impeller blades mounted along the shaft. Gases were introduced with a sparger placed beneath the impellers. Four vertically mounted baffles along the sides of the reactor enhanced the mixing.

The agitator was powered by a variable speed motor ( 0 to $850 \mathrm{rpm})$. The impeller speed was measured by a tachometer (Cole Parmer).

The aeration rates were measured with a rotameter at the inlet. The air flow was measured in litre per minute and could be varied from 0.1 to 2 litre per min.

Dissolved oxygen was measured with an Ingold permeable membrane probe and a Cole Parmer 0197100 digital D.O. meter giving readings as $\mathrm{mg} / \mathrm{L}$. The probe was installed near the side wall in the bottom half of the vessel. The D.O. probe was calibrated and tested before insertion into the vessel. 


\subsubsection{Experimental Design}

\subsubsection{Agitation-Aeration System}

The experimental design consisted of six aeration rates $(0.05,0.1,0.16$, $0.2,0.28,0.48 \mathrm{vvm}) \mathrm{com}^{\prime}$ sred at steady agitation (500 rpm) using 0 or $20 \%$ (v/v) of microencapsulated silicone oils. Moreover, three agitation rates (225, $500,725 \mathrm{rpm})$ were compared at steady aeration rates $(0.3 \mathrm{vvm})$ in the absence or presence $(20 \% \mathrm{v} / \mathrm{v})$ of microcapsules. The microcapsules were saturated with air and then introduced into the deoxygenated aqueous phase.

All the $k_{\mathrm{L}} \mathrm{a}$ experiments were carried out with 1.0 litre of water in the vessel. Therefore, $1 \mathrm{LPM}$ of air flow rate corresponded to one volume per volume per minute (vvm). The air flow rate and the experimental value of $\mathrm{k}_{\mathrm{L}} \mathrm{a}$ were referred to the aqueous volume without taking into account the volume of microcapsules.

\subsubsection{Non-aeration System}

Similar procedures as above were followed except without aeration. Therefore, the deoxygenated aqueous phase was re-aerated solely by the 
microcapsules. Five volume fractions $(10,15,20,25,30 \%)$ of microcápsules were compared at constant agitation rate of $500 \mathrm{rpm}$.

\subsection{Fermentation}

\subsubsection{Rehydration of Bacteria}

The strain used in the fermentation experiments was Gluconobacter oxydans suỏsp. suboxydans. It was obtained from American Type Culture Collection designated as ATCC 621.

Lyophilized cultures were stored at $-18^{\circ} \mathrm{C}$. Rehydrated cells $(0.1 \mathrm{~g}$ dry wt $/ 100 \mathrm{ml}$ medium) were cultured in liquid medium for 24 hours at 28 to $30^{\circ} \mathrm{C}$. The medium was sterilized for 30 minutes at $121^{\circ} \mathrm{C}$ prior to use. 


\subsubsection{Cultivation of Bacteria}

The stock culture was maintained on sterilized agar slants at $4{ }^{\circ} \mathrm{C}$ of the following composition (in $\mathrm{g} / \mathrm{l}$ ):

$\begin{array}{ll}\text { glycerol } & 50 \\ \text { yeast extract } & 5 \\ \text { peptone } & 3 \\ \mathrm{NH}_{4} \mathrm{Cl} & 0.8 \\ \mathrm{Na}_{2} \mathrm{HPO}_{4} \cdot 2 \mathrm{H}_{2} \mathrm{O} & 0.6 \\ \mathrm{KH}_{2} \mathrm{PO}_{4} & 0.4 \\ \mathrm{MgSO}_{4} \cdot 7 \mathrm{H}_{2} \mathrm{O} & 0.2 \\ \mathrm{Agar} & 20 \\ (\mathrm{CaCl} & 1.1)\end{array}$

Glycerol was the main carbon source and the yeast extract was provided as nitrogen source. The culture was reinoculated on new agar slants every month. Liquid growth medium had the same composition, except agar was not added. In some of the experiments where cells were immobilized in Ca-alginate beads, $10 \mathrm{mM}$ $\mathrm{CaCl}_{2}$ were added to the medium in order to stabilize the beads. 


\subsubsection{Estimation of Biomass Concentration}

Optical Density (O.D.) was measured at $600 \mathrm{~nm}$ with a Varian Cary UVvisible spectrophotometer. Millipore water was used as blank. It was found that one O.D. unit corresponds to $706 \mathrm{mg}$ litre ${ }^{-1}$ dry weight. A standard curve for cell density was plotted and the relationship is as follows:

Cell Density $(\mathrm{g} / \mathrm{L})=($ Absorbence -0.02575$) / 1.38$

The biomass concentrations were also measured by the dry weight of the samples of the fermentation brotn. After centrifuging $20 \mathrm{ml}$ of cell suspension at $6000 \mathrm{rpm}$ for 25 minutes, the pellets obtained were washed with Millipore water and dried over-night at $105^{\circ} \mathrm{C}$ to a constant weight.

\subsubsection{Quantification of Dihydroxyacetone}

In the presence of oxygen, Gluconobacter suboxydans is able to convert glycerol to dihydroxyacetone (DHA). The amount of DHA produced is used as an indicator of the oxygen supply in the preparation. Quantification of DHA was performed with the DNS-method of Miller et al. ${ }^{29}$ which had been modified by Aldercreutz and Mattiasson ${ }^{3}$. DHA was oxidized by dinitrosalicylic acid and a coloured complex was formed. One $\mathrm{ml}$ of the sample was mixed with $1 \mathrm{ml}$ of DNS- 
reagent and $5 \mathrm{ml}$ of Millipore water. The absorbence was measured with a Varian Cary spectrophotometer at $575 \mathrm{~nm}$. The standard curve of DHA was plotted and the relationship was found to be:

$[\mathrm{DHA}](\mathrm{mM})=$ Absorbance $/ 0.088824$

\subsubsection{Batch Fermentation}

\subsubsection{Inoculum}

Gluconobacter oxydans from the agar slants was incubated in $500 \mathrm{ml}$ Erlenmeyer flasks containing $150 \mathrm{ml}$ culture medium, on a rotary shaker (220 $\mathrm{rpm}$ ) at $28^{\circ} \mathrm{C}$. After $24 \mathrm{hrs}, 50 \mathrm{ml}$ of the medium was transferred to $150 \mathrm{ml}$ fresh medium and shaken for $24 \mathrm{hrs}$. This culture was used as the inoculum for a 2litre batch fermenter. The medium used to prepare the inoculum was the same as that used for the fermentation. The medium in the 2-litre fermenter was inoculated with $10 \%(v / v)$ inoculum.

\subsubsection{Batch Fermentation Conditions}

The batch fermentation of Gluconobacter oxydans was carried out at $28^{\circ} \mathrm{C}, 1 \mathrm{~atm}$, and $\mathrm{pH} 6.0$ in defined minimal media as described above in microcapsule-in-water dispersions overmicrocapsule volume fraction s between 
0 and $20 \%(\mathrm{v} / \mathrm{v})$. Fermentation was performed in a 2-L fermenter of 1.3 litre working volume. The agitation and aeration rates were $450 \mathrm{rpm}$ and $0.3 \mathrm{vvm}$ respectively. All equipment and liquid media were sterilized in the autoclave $\left(121^{\circ} \mathrm{C}\right.$ and $2 \mathrm{~atm}$ for $\left.25 \mathrm{mins}\right)$ before inoculation. The inlet and exhaust air was sterilized by passing through a packed fiber-glass filter.

The dissolved oxygen concentration was monitored by an Ingold sterilizable D.O. probe connected to a Cole Parmer digital D.O. analyzer. The temperature control was achieved by a solid state controller with a thermowell mounted thermistor sensor and a heater element.

\subsubsection{Fluidized Bed Fermentation}

\subsubsection{Immobilization of Cells}

$3.6 \mathrm{~g}$ of sodium alginate was dissolved in $100 \mathrm{ml}$ of distilled water with the aid of a homogenizer. The alginate solution $(3.6 \% \mathrm{w} / \mathrm{w})$ was then sterilized in an autoclave $\left(121^{\circ} \mathrm{C}\right.$ and $\left.2 \mathrm{~atm}\right)$ for $15 \mathrm{mins}$. A cell suspension of known cell density in the culture medium was mixed with an equal volume of $3.6 \%(w / w)$ sodium alginate. The final alginate concentration was $1.8 \%(\mathrm{w} / \mathrm{w})$. The mixture was pumped through a sterile hypodermic needle $(0.9 \mathrm{~mm}$ I.D.) and dropped $10 \mathrm{~cm}$, into a $0.1 \mathrm{M}$ pre-sterilized $\mathrm{CaCl}_{2}$ solution. The $\mathrm{Ca}$-alginate gel beads 
containing cells, were stabilized in the $\mathrm{CaCl}_{2}$ solution for an hour. The beids were then filtered off and stored in the pre-sterilized peptone water containing $10 \mathrm{mM} \mathrm{CaCl}_{2}$ at $4^{\circ} \mathrm{C}$ until use. The density of the $\mathrm{Ca}$-alginate gel beads was $1027 \mathrm{~kg} / \mathrm{m}^{3}$ (ref. 5) and the mean diameter was about $0.2 \mathrm{~cm}$. The cell density in the beads was $35 \mathrm{mg}$ cell (dry weight) per $\mathrm{g}$ wet gel.

\subsubsection{Experimental Set-up}

The reactor was constructed of transparent arcylic glass with an inner diameter of $3.8 \mathrm{~cm}$ and a height of $16 \mathrm{~cm}$. Both ends of the reactor were sealed with stainless steel mesh screen of pore size $0.12 \times 0.12 \mathrm{~cm}$. The purpose of the mesh screen was to ensure the Ca-alginate gel beads stay in the reactor while allowing the microencapsulated silicone oil (mean diameter $=100 \mu \mathrm{m}$ ) free passage.

The culture medium containing $50 \mathrm{mM}$ glycerol as substrate for the bacteria, and $10 \mathrm{mM} \mathrm{CaCl}_{2}$ to stabilize the $\mathrm{Ca}$-alginate gel beads, was pumped from the bottom of the reactor. The effluent then entered the aeration section through a shower head for enhancing oxygen transfer surface area. The aeration section has an inner diameter of $3.8 \mathrm{~cm}$ and a height of $20 \mathrm{~cm}$, in which $9 \mathrm{~cm}$ was the liquid level and $11 \mathrm{~cm}$ was the head space. Sterile aur was 
introduced into the liquid level of the aeration section and purged from the top. The culture medium containing pre-dissolved oxygen was recirculated into the reactor. The total liquid volume in the fluidized bed fermenter was $400 \mathrm{ml}$. The liquid flow rate was $100 \mathrm{ml} / \mathrm{min}$ and the air flow rate was $0.35 \mathrm{LPM}$. The dissolved oxygen concentration was measured by the oxygen probes which were placed in both the inlet and outlet of the reactor.

\section{Fluidized Bed Fermentation}

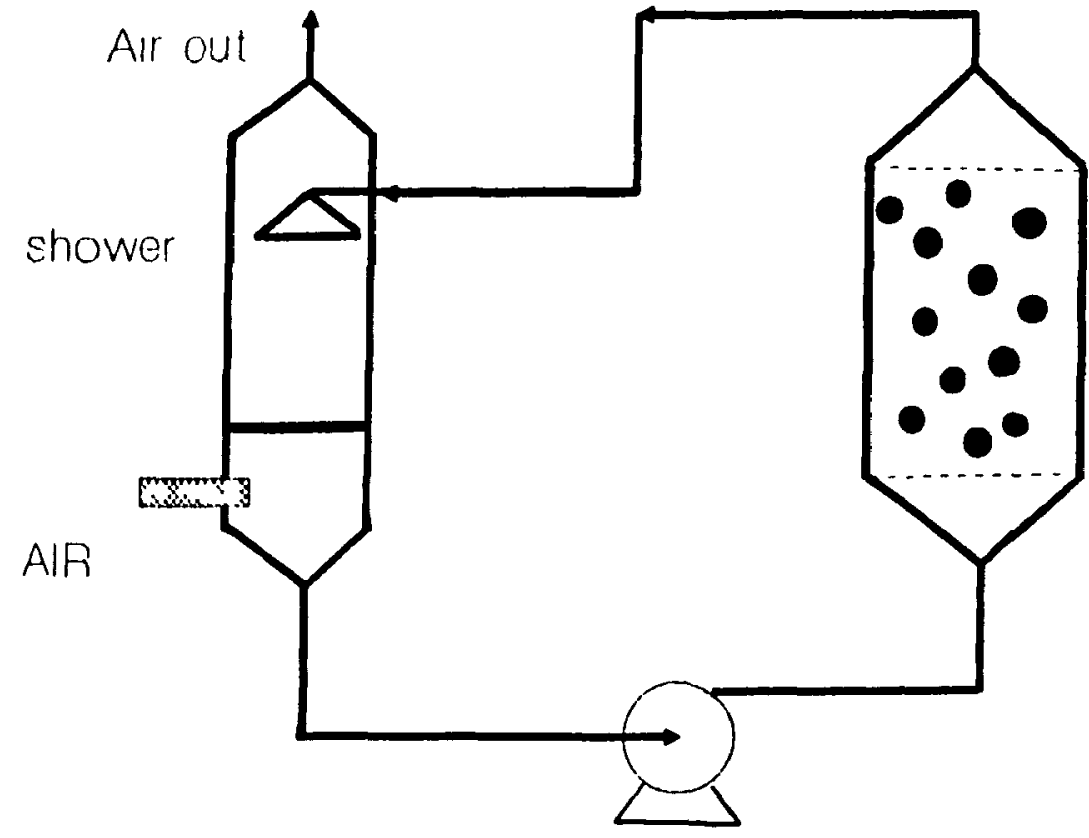

mesh

(1 $\mathrm{mm}$ )

immobolized cells $(2 \mathrm{~mm})$

Figure 5. Fluidized Bed Fermentation Set-up 


\section{1) R IISUIITS}

\section{Preparalion of mictocapsules}

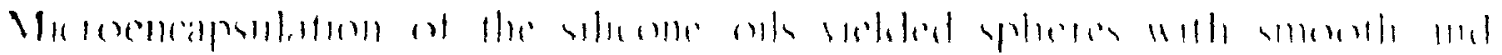

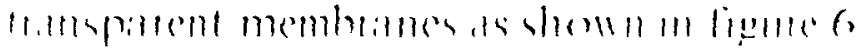

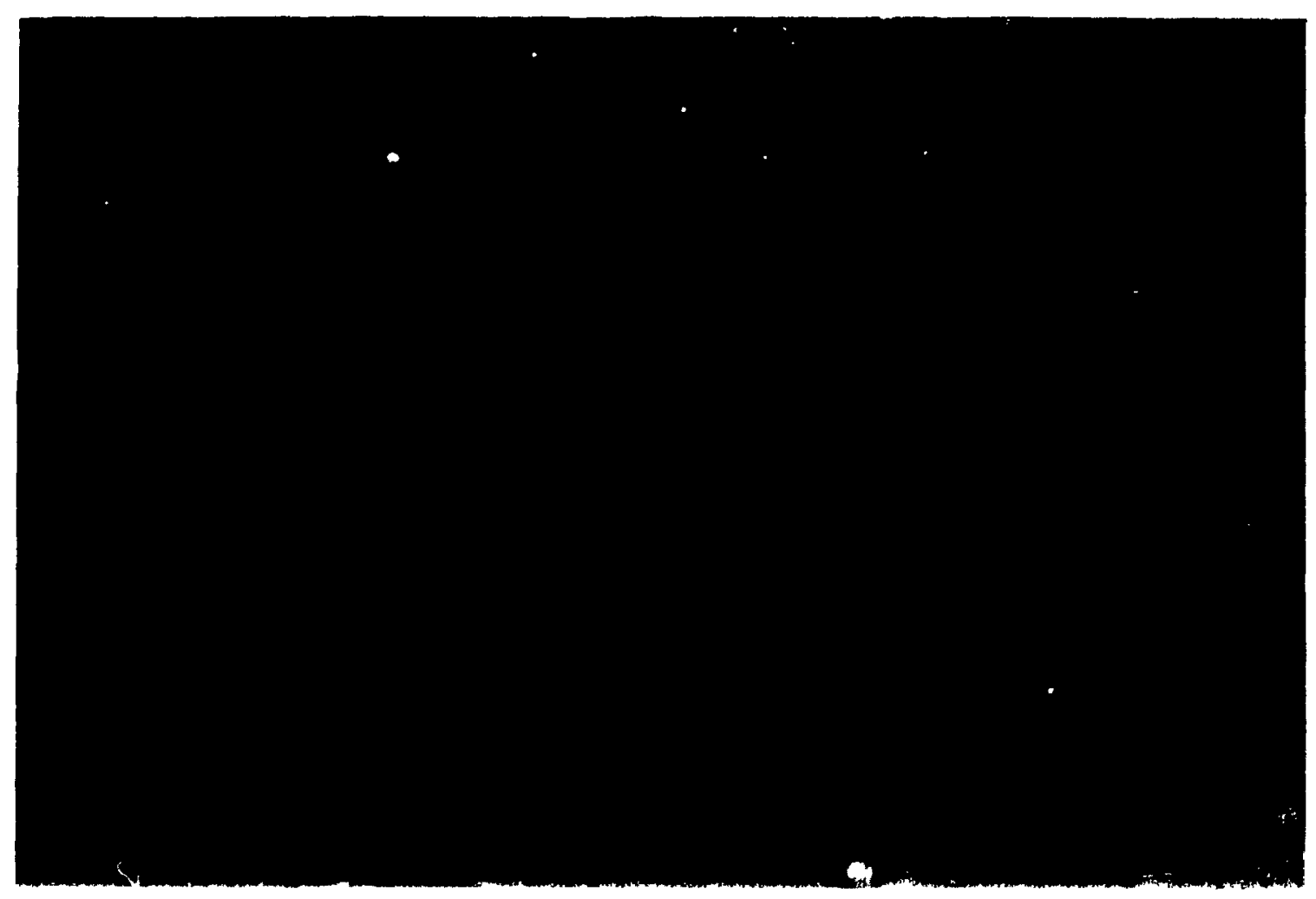

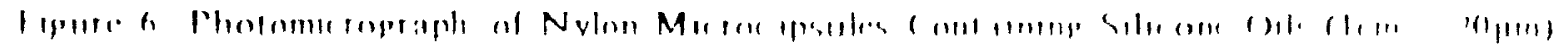


The test conditions for polyamide membrane formation via interfacial polymerization are presented in table 1.

\begin{tabular}{|c|c|c|c|}
\hline $\begin{array}{l}\text { Bencent or Conditions } \\
\text { DIchloride: } \\
\text { Trephthal oyl } \\
\text { Trimesoyl } \\
\text { Sebacoyl }\end{array}$ & $\begin{array}{r}\text { Datails } \\
0.04-0.1 \mathrm{M} \\
0.04-0.1 \mathrm{M} \\
<0.05 \mathrm{M} \\
>0.05 \mathrm{M}\end{array}$ & $\begin{array}{c}\text { Clnsi' } \\
- \\
- \\
++ \\
++\end{array}$ & $\begin{array}{l}\text { Motes } \\
\text { No capsules formed } \\
\text { No capsules } \\
\text { Water entrainment }\end{array}$ \\
\hline silicone olls & $\begin{array}{r}1 \mathrm{cs} \\
5,1050 \mathrm{cs}\end{array}$ & $\begin{array}{l}++ \\
++\end{array}$ & Volatile, expensive \\
\hline $\begin{array}{l}\text { Hexanced lamine } \\
+ \text { Polyethylen } 1 \text { mine }\end{array}$ & $\begin{array}{l}0.1-0.2 \mathrm{M} \\
0.4-0.6 \mathrm{M} \\
2=(\mathrm{v} / \mathrm{V})\end{array}$ & $\begin{array}{l}++ \\
++ \\
+++\end{array}$ & $\begin{array}{l}\text { Not very strong } \\
\text { Not very strong } \\
\text { Very strong }\end{array}$ \\
\hline Aqueous solution $\mathrm{pH}$ & $\begin{array}{ll}\text { pH } & 8 \\
\text { pH } & 9 \\
\text { pH } & 10 \\
\text { pH } & 11\end{array}$ & $\begin{array}{c}+ \\
++ \\
++ \\
++\end{array}$ & \\
\hline $\begin{array}{l}\text { Phase volume ratio } \\
\text { (organic.aqueous) }\end{array}$ & $\begin{array}{l}1: 4 \\
1: 3 \\
1: 2.5\end{array}$ & $\begin{array}{l}++ \\
++ \\
++\end{array}$ & \\
\hline $\begin{array}{r}\text { Turbane: Sheet } \\
\text { Frame }\end{array}$ & & $\begin{array}{l}+ \\
++ \\
++\end{array}$ & \\
\hline T'urbine speed & $\begin{array}{l}250 \mathrm{rpm} \\
300-400 \mathrm{rpm} \\
450 \mathrm{rpm} \\
>450 \mathrm{rpm}\end{array}$ & $\begin{array}{c}+ \\
++ \\
++ \\
++\end{array}$ & Poor emulsion \\
\hline $\begin{array}{r}\text { Surfactants: Tween } 20 \\
\text { Tween } 80 \\
\text { Pluronic acid } \\
\text { Dow } 190\end{array}$ & $\begin{array}{l}1 \text { to } 58(v / v) \\
1 \text { to } 58(v / v) \\
1 \text { to } 108(v / v)\end{array}$ & $\begin{array}{l}- \\
- \\
+ \\
++\end{array}$ & Good emulsion \\
\hline Einulsion Time & $\begin{array}{l}1 \mathrm{~min} \\
1.5 \mathrm{~min} \\
2 \mathrm{~min} \\
2.5 \mathrm{~min}\end{array}$ & $\begin{array}{c}+ \\
++ \\
++ \\
++\end{array}$ & \\
\hline Reaction Time & $\begin{array}{l}2 \mathrm{man} \\
2.5 \mathrm{~min} \\
3 \mathrm{~min} \\
>3 \mathrm{~min}\end{array}$ & $\begin{array}{c}+ \\
++ \\
++ \\
++\end{array}$ & \\
\hline
\end{tabular}

Thicrocapsule chesification: +++ very good, ++ good, + eatisiactory, - poor

Table 1. Test Conditions for Nylon Membrane Formation 
Low viscosity ( $1 \mathrm{cs})$ silicone resulted in stronger microcapsules, and the acid dichloride was not completely soluble in high viscosity silicone $(50 \mathrm{cs})$. Using 40-100 $\mathrm{mM}$ trephthaloyl and trimesoyl chloride as oil soluble reactants resulted in reduced yields. Sebacoyl chloride promoted strong membranes at an optimum concentration of 45 to $50 \mathrm{mM}$. At higher concentrations, microcapsules were less stable or were irregularly shaped.

Different concentrations of hexanediamine, with or without the addition of branched polyethylenimine (PEI) ascross-linker, were tested. Intact microcapsules with stronger membranes were obtained using $0.4 \mathrm{M}$ hexanediamine aqueous solution and cross-linked with $2 \%(v / v)$ PEI solution. The microcapsule suspension was autoclaved for 20 mins at $121^{\circ} \mathrm{C}$ and 1 atm without breakage or change in physical properties. Thus, the microcapsules are heat-stable and able to withstand sterilization conditions.

The $\mathrm{pH}$ of the aqueous solution did not appear to strongly influence polymerization. However, best results were obtained with $\mathrm{pH} 10$.

Of the four surfactants tested, only Dow 190 promoted good emulsification. The concentration of surfactant affected the mean size of the preparation as will be shown but not the appearance. Intact microcapsules were obtained at all rotational speeds tested with a turbine impeller, however stronger microcapsules with the lowest broken fraction were obtained at $450 \mathrm{rpm}$ when using a frame lattice mixer. 
Emulsification and reaction time are optimum at 2 and 3 minutes respectively. The volume ratio of silicone was maintained less than $20 \%$ of the emulsion volume.

\subsection{Microcapsule Size Distribution}

According to Poncelet et al. ${ }^{32}$, the silicone microcapsule preparations resulted in broad size distributions using a $150 \mathrm{ml}$ vessel ( $50 \mathrm{~mm}$ internal diameter) and a $45 \times 10$ mm sheet mixer. The mean size varied between $100 \pm 35$ and $300 \pm 141 \mu \mathrm{m}$.

In this study, the vessel was slightly modified. It was mounted with four vertical baffles along the sides and the sheet lattice mixer was longer $(70 \times 10 \mathrm{~mm})$. The mean size of the microcapsules obtained varied between $50 \pm 34 \mu \mathrm{m}$ and $200 \pm 85 \mu \mathrm{m}$ due to the enhanced mixing in the baffled reactor.

The mean diameter of the microcapsule preparation decreased from 150 to $50 \mu \mathrm{m}$ as the surfactant concentration increased from 1 to $10 \%(\mathrm{v} / \mathrm{v})$ during emulsification. The distribution curves are shown in figure 6. 


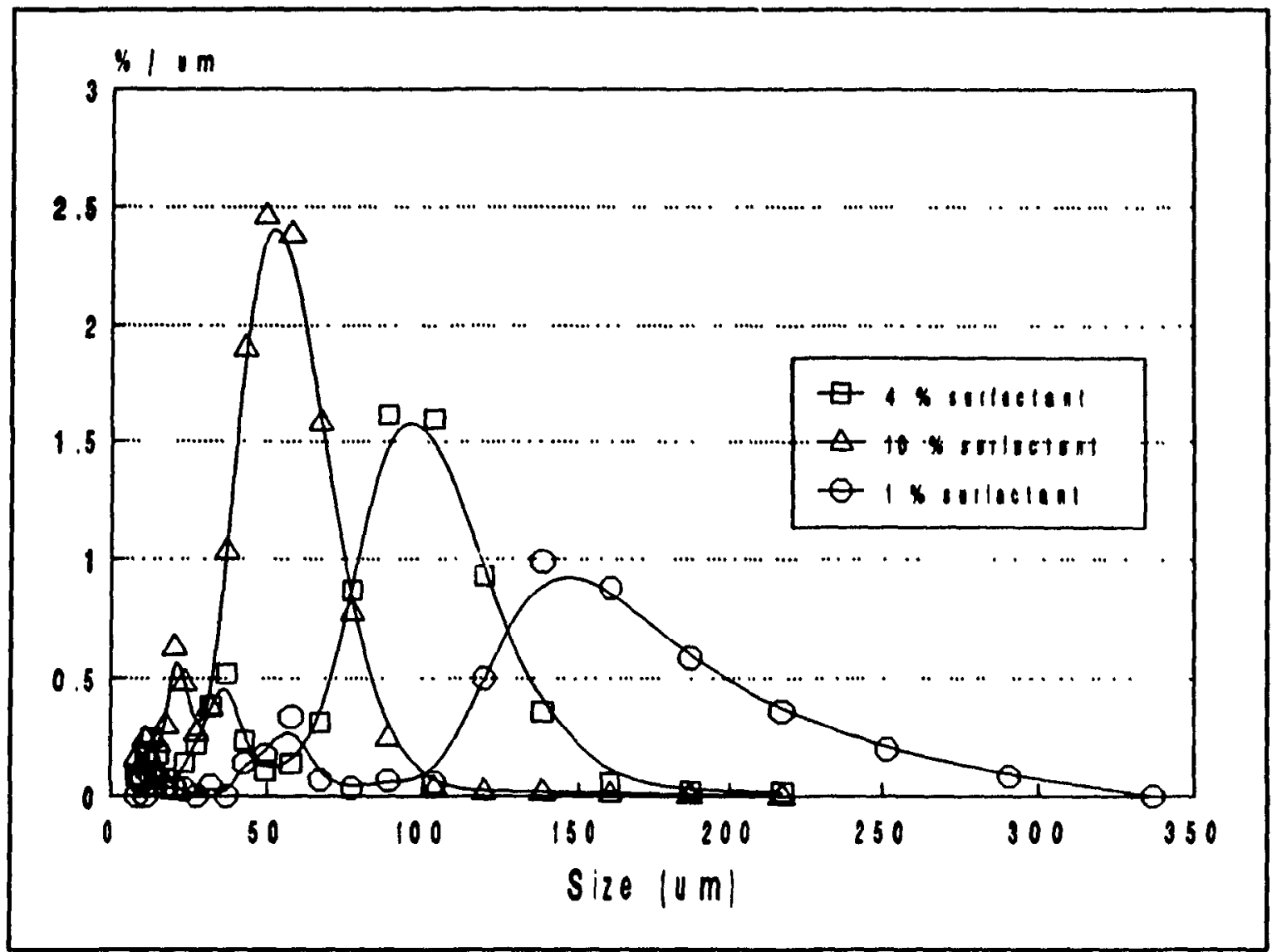

Figure 7. Impact of Surfactant Concentration on Microcapsule Size Distribution

It was also possible to control the mean diameter by varying the turbine rotational speed as illustrated in figure 8 . The mean diameter ranged from 130 to $330 \mu \mathrm{m}$ when the rpm was varied between 200 and 700 . 


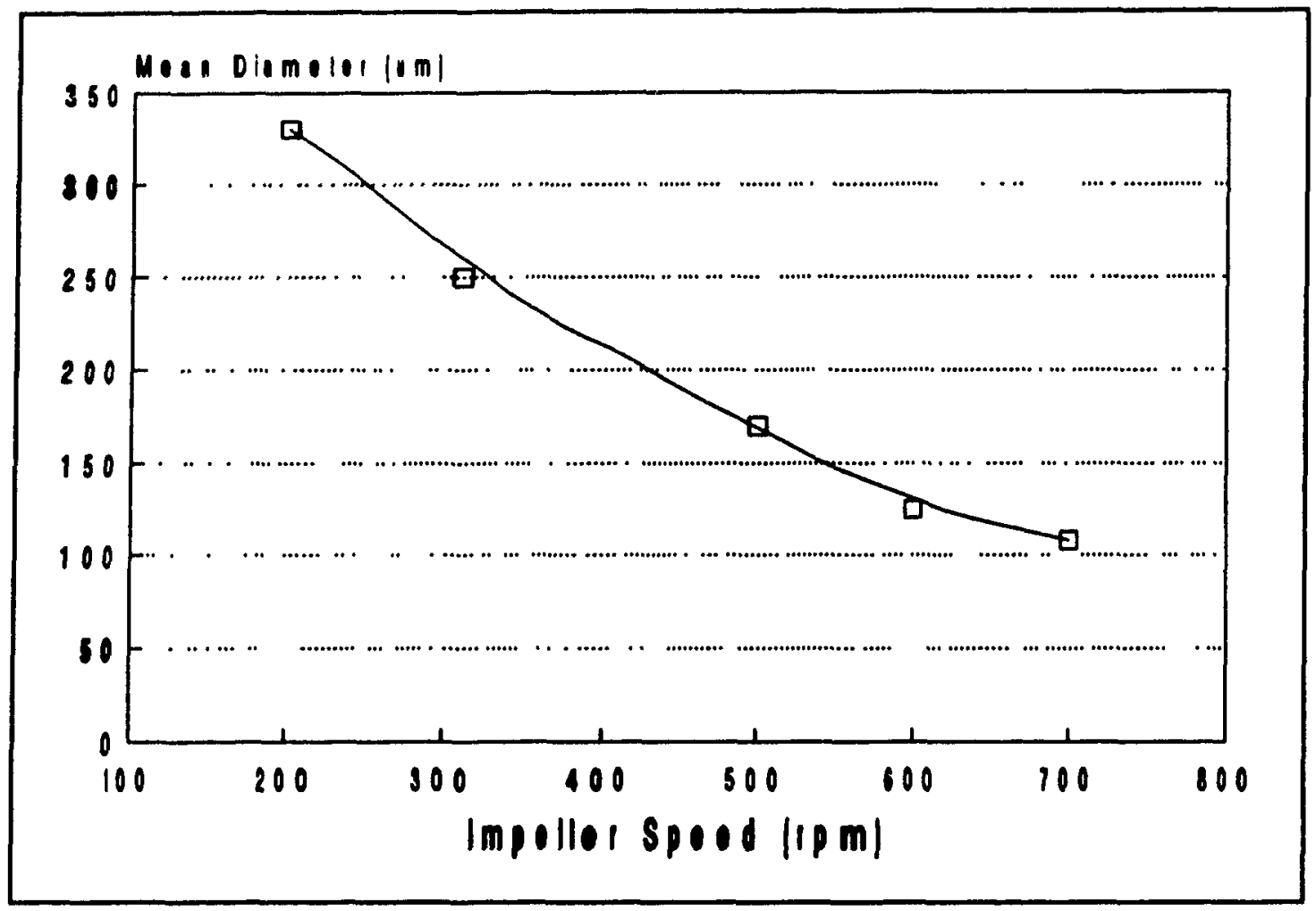

Figure 8. Effect of Turbine Rotational Speed on Mean Microcapsule Diameter

Other tested parameters (Table 1) had minimal impact on mean diameter. No real dependence was observed between the standard deviation and the operating conditions. 


\subsection{Oxygen solubility in silicone oils and other solvents}

Oxygen solubility and partition coefficient were determined using sulphite as an oxygen sink. Values are tabulated (table 2) for silicones of varying viscosity, in comparison to that of microencapsulated $10 \mathrm{cs}$ silicone oil.

\begin{tabular}{|c|c|c|c|c|c|c|}
\hline & \multirow[t]{2}{*}{ Water } & \multicolumn{4}{|c|}{ Silicone Oils } & \multirow{2}{*}{$\begin{array}{l}\text { Micro- } \\
\text { capsules }\end{array}$} \\
\hline & & $1 \mathrm{cs}$ & $5 \mathrm{cs}$ & $10 \mathrm{cs}$ & $50 \mathrm{cs}$ & \\
\hline$\left[\mathrm{O}_{2}\right](\mathrm{mM})$ & 0.28 & 6.0 & 5.4 & 5.8 & 5.3 & 6.01 \\
\hline $\mathbf{K}$ & 1 & 21 & 19 & 20 & 18 & 24 \\
\hline
\end{tabular}

Table 2. Oxygen Solubility and Partition at $25^{\circ} \mathrm{C}$

The solubility of oxygen in silicone oils, relative to that of water, was enhanced by approximately 20 fold, including that of the microencapsulated form. Solubilities ranged from 5.3 to $6.0 \mathrm{mM}$, with no correlation evident to the silicone viscosity. As a comparison, reported values of oxygen solubility in a variety of other solvents are listed in table 3. 


\begin{tabular}{|c|c|c|c|}
\hline Compound & $\mathbf{K}$ & $\mathrm{T}\left({ }^{\circ} \mathrm{C}\right)$ & Reference \\
\hline Hexane & 6.9 & 30 & McMillan, $1987^{47}$ \\
\hline Hexanedacane & 4.0 & 18 & McMillan, $1987^{47}$ \\
\hline \multirow[t]{2}{*}{ Paraffin Oil } & 3.9 & 30 & Yoshida, $1970^{49}$ \\
\hline & 3.3 & 30 & McMillan, $1987^{47}$ \\
\hline \multirow[t]{3}{*}{ Perfluorodecalin } & 16.9 & 37 & King, $1989^{28}$ \\
\hline & 9.2 & 37 & Leonhardt, $1985^{25}$ \\
\hline & 12.6 & 25 & Mattiason, $1987^{6}$ \\
\hline Perfluorocarbon & & & \\
\hline FC-40 & 11.6 & 30 & McMillan, $1987^{47}$ \\
\hline FC-45 & 11.3 & 30 & McMillan, $1987^{47}$ \\
\hline FC-75 & 15.9 & 30 & McMillan, $1987^{47}$ \\
\hline Polydimethylsiloxane & 14.0 & 30 & Leonhardt, $1985^{25}$ \\
\hline Hemoglobin $(350 \mathrm{~g} / \mathrm{l})$ & 66.4 & 20 & Computed \\
\hline
\end{tabular}

Table 3. Comparison of Partition Coefficients of Different Oxygen Carriers

Partition coefficients range widely from 3.3 for paraffin oil to 16.9 for perfluorodecalin. Oxygen solubility in the silicone oils is almost double that of the fluorocarbons FC-40 and FC-45 and 1.3 times higher than that of FC-75. Hemoglobin was estimated to bind oxygen to levels of 66.4 times that of oxygen solubility in water. 


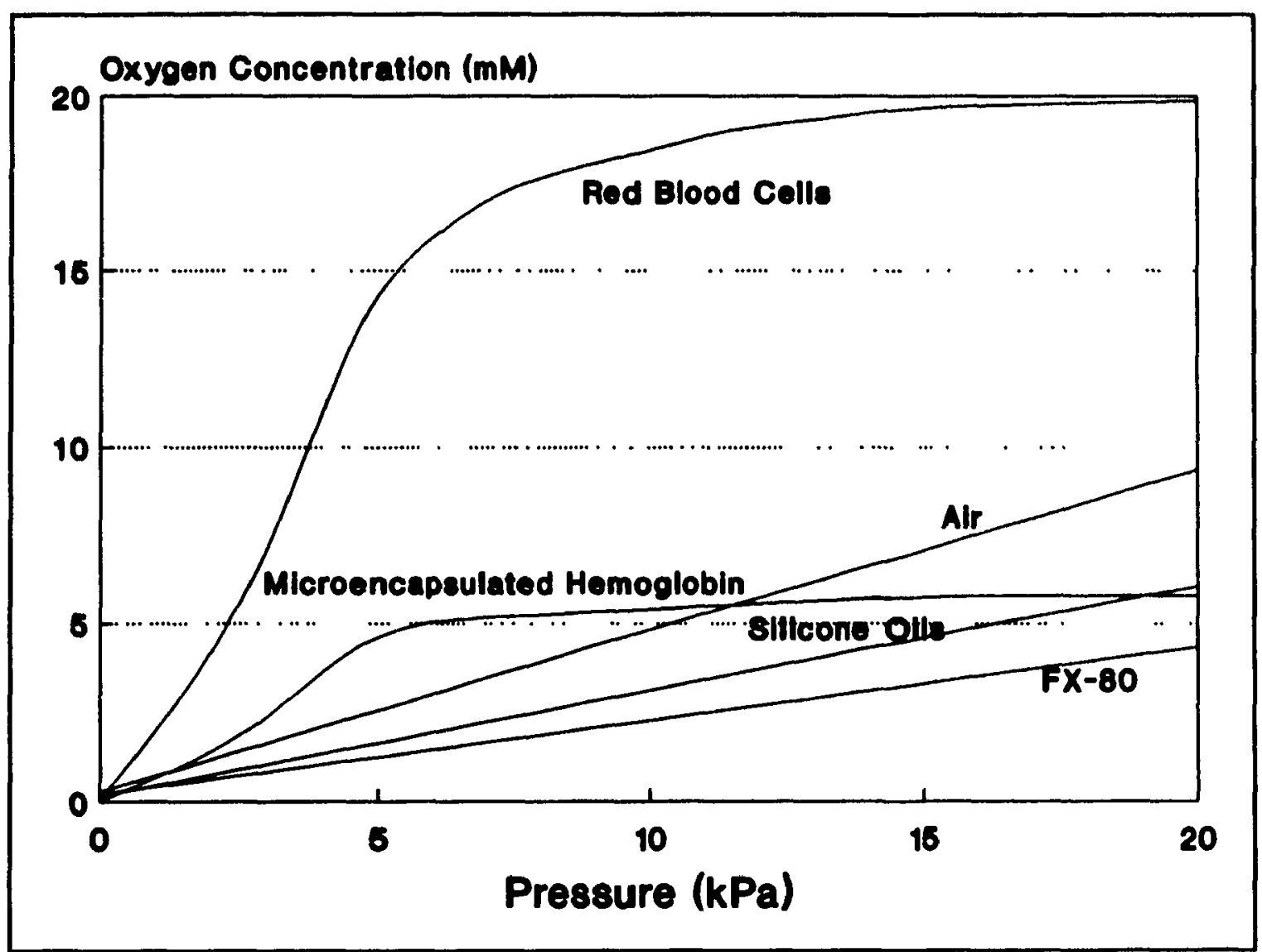

Figure 9. Oxygen Concentration in Function of Different Pressure for Certain Oxygen Carricrs

Oxygen concentration as a function of pressure is plotted in figure $9^{32}$ for a few materials including microencapsulated hemoglobin, and red blood cells. A linear correlation was observed for silicone oil and fluorocarbon FX-80, while a sigmoidal-type relationship wasobserved representing oxygen binding to red blood cells and microencapsulated hemoglobin. 


\subsection{Mass Transfer of Oxygen From Microencapsulated Oxygen Carriers}

\subsubsection{Oxygen Electrode Response Time}

Figure 10. shows the response of the Ingold dissolved oxygen electrode a step change in D.O. concentration. The time constant for the probe was 10.5 seconds. As the probe membranes were repeatedly autoclaved, the response time increased. For example, the response time was observed to be 16 seconds after 10 cycles of steam sterilization. It is recommended that the probe membranes be replaced every 20 sterilization cycles to achieve a better probe response.

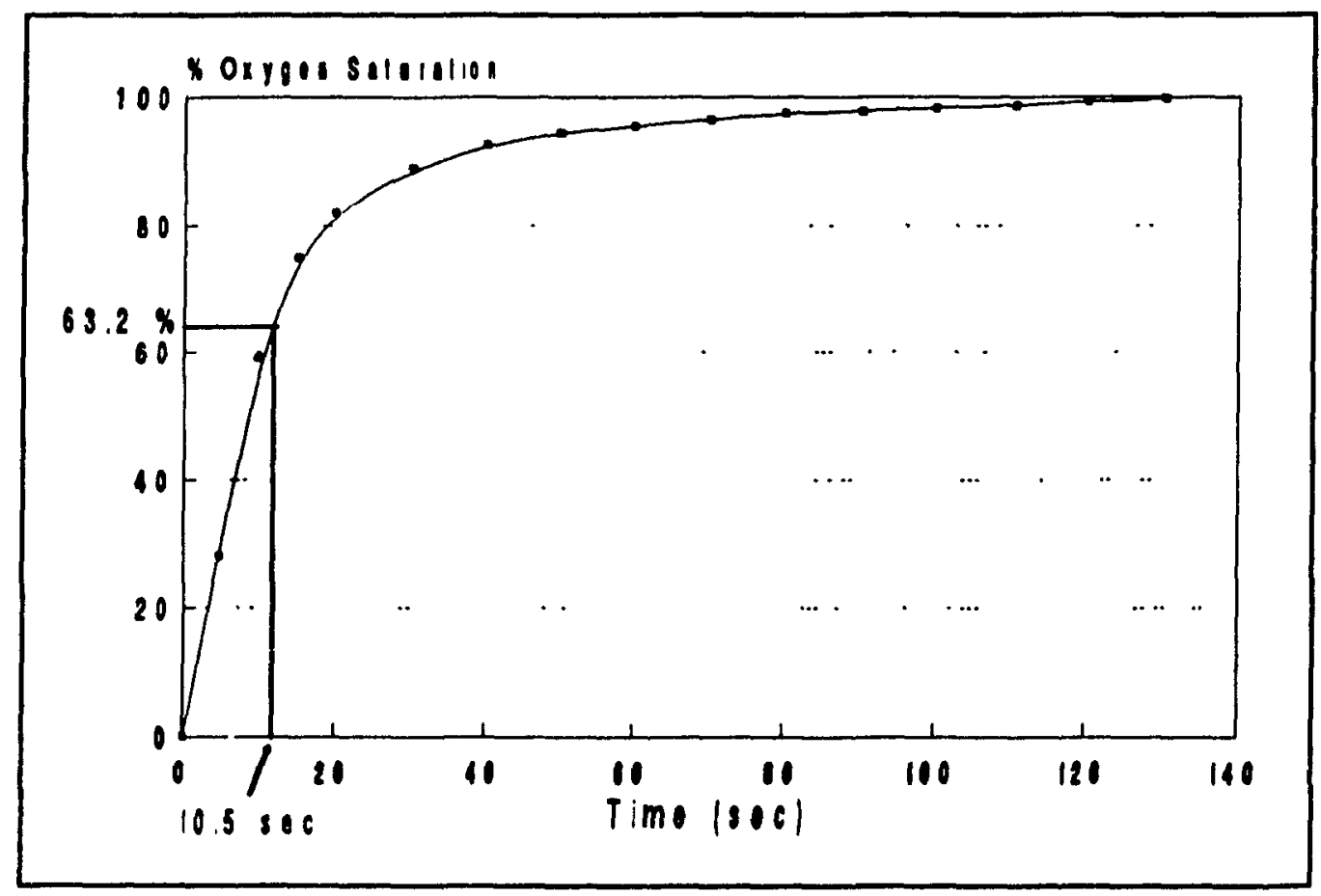

Figure 10. Response Time of the Ingold Oxygen Electrode 


\subsubsection{Oxygen Electrode Dynamics}

The response of the oxygen electrode was subject toa delay, mainly caused by the oxygen diffusion through the electrolyte layer separating the inside surface of the membrane from the surface of the cathode. This effect might greatly influence the dynamic $\mathrm{k}_{\mathrm{L}}$ a measurements, especially during high aeration capacity, due to the fact that the rate of oxygen transfer from gas to liquid was comparable with the rate of oxygen diffusion via the membrane to the cathode. Failure to take into account of such oxygen electrode dynamic effects could cause errors in the determination of $\mathrm{k}_{\mathrm{L}}$ a of up to $100 \%{ }^{38}$

A graphical approach of the integrated form of eq.(1) was suggested by Fujita and Hashimoto ${ }^{14}$. By introducing a normalized variable - normalized probe response, $Y_{p}$ into eq. (1):

$$
Y_{p}=\left(C^{*}-C_{1}\right) /\left(C^{*}-C_{L O}\right)
$$

where $\mathrm{C}_{\mathrm{LO}}=\mathrm{D} . \mathrm{O}$. concentration at $\mathrm{t}=0$, and integrating, the following relation was obtained,

$$
Y_{p}=\exp \left(-k_{L} a t\right)
$$


Taking into account the probe dynamics, the probe response was expressed by the first order lag function:

$$
d Y_{p} / d t=K_{p}\left(Y_{L}-Y_{p}\right)=\left(Y_{L}-Y_{p}\right) / T_{p}
$$

where $Y_{L}=$ normalized oxygen concentration in liquid phase,

$$
\begin{aligned}
& \mathrm{K}_{\mathrm{p}}=\text { probe constant }\left(\mathrm{s}_{-1}\right), \\
& \mathrm{T}_{\mathrm{p}}=\text { probe time constant }(\mathrm{s}) .
\end{aligned}
$$

The initial conditions $t=0, Y_{p}=1, Y_{L}=1$ yielded the following relation:

$$
Y_{p}=\left[K_{p} \exp \left(-k_{L} a t\right)-k_{L} a \exp \left(-K_{p} t\right)\right] /\left(K_{p}-k_{L} a\right)
$$

Determination of $k_{\mathrm{L}}$ a could be achieved either by non-linear regression estimation techniques, or by the method of moments ${ }^{38}$. In this study, the latter was used to modify the dynamic $\mathrm{k}_{\mathrm{L}}$ a measurement in order to characterize the oxygen electrode delay. 
The method of moments was based on area measurements on the normalized electrode output versus time plot. Using the following equation:

$$
1 / k_{L} a=\alpha_{c}-\alpha_{s}=\int\left(1-Y_{p}\right) d t-\int\left(1-Y_{p}^{1}\right) d t
$$

where $\alpha_{c}$ was the area above the chart of the transient aeration experiment. $\alpha_{s}$ was the area above the recorder chart of the electrode step response experiment (see figure 11). The final plot was composed of two curves. The first, $Y_{p}{ }_{p}^{1}$, represented the electrode response to a step change in oxygen concentration, while the second, $Y_{p}$ was the normalized trace of an actual aeration experiment. The area between the two curves, obtained as $\alpha_{e}-\alpha_{s}$, was the reciprocal of $k_{L} a$. An example is shown in figure 11. 


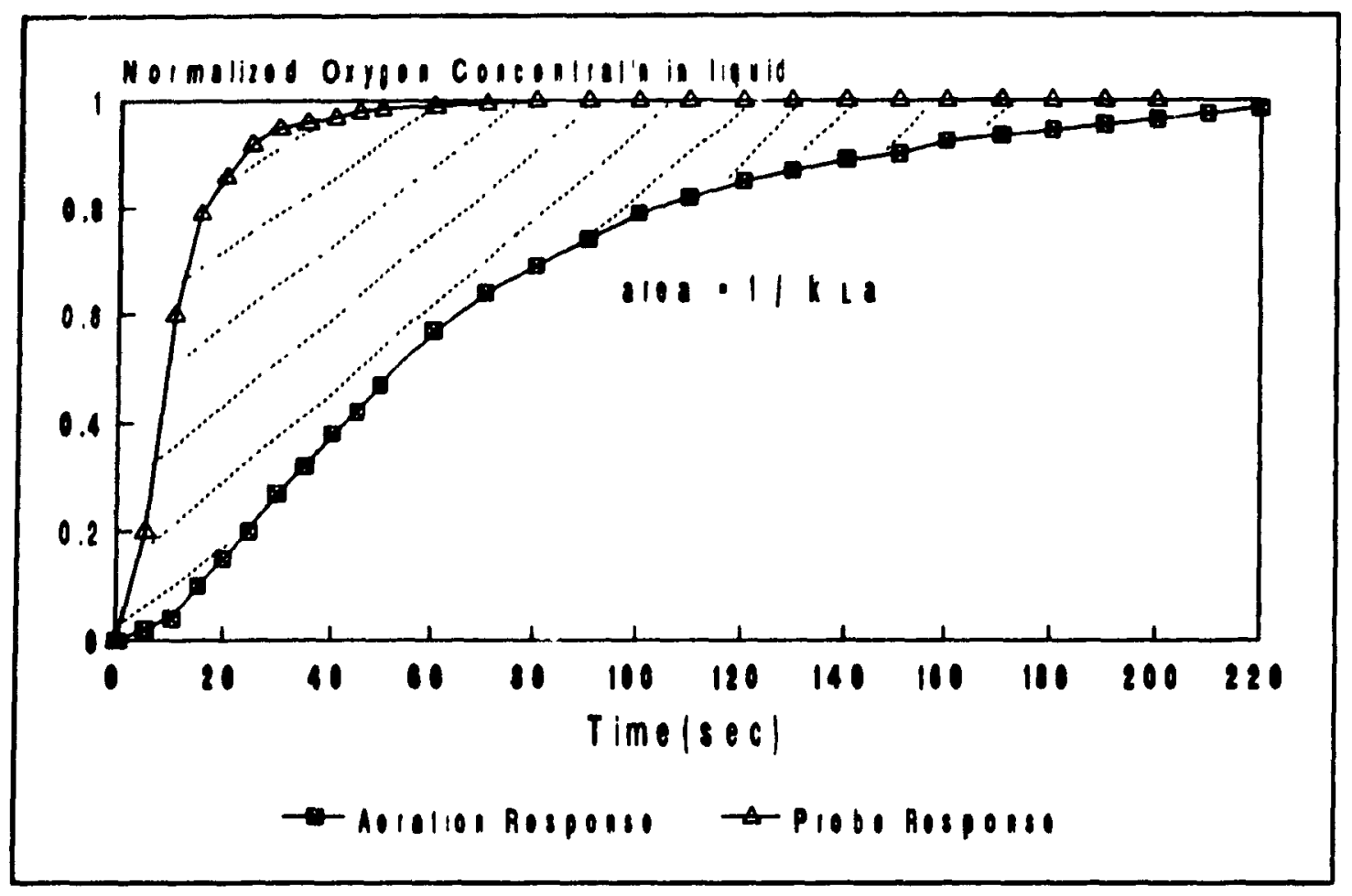

Figure 11. Determination of $k_{\mathfrak{t}}$ a by Method of Moments using a 1.5-litre vessel with no respiring cells presence. The air flow rate was 0.15 vvm and the agitation rate was 550 rpm. The $k_{L^{a}}$ measured by the dynamic method was $64 \mathrm{hr}^{-1}$ and by the method of moments was 77 hr'.

\subsection{3 $k_{L}$ a Measurements without Cells}

\subsubsection{Non-aerated system $-k_{L} a$ Measurement}

In the absence of bubble aeration, the oxygen transfer coefficient, $k_{\mathrm{L}} \mathrm{a}$, for microencapsulated oxygen carriers-to-water using different microcapsule volume fractions was measured by the dynamic method. As seen in figure 12, as the volume fraction of the microcapsules was increased from $10 \%$ to $30 \%$, the 
$\mathrm{k}_{\mathrm{L}}$ a value increased from 125 to $188 \mathrm{hr}^{-1}$. The $0 \%$ on the graph represents the oxygen transfer through surface aeration.

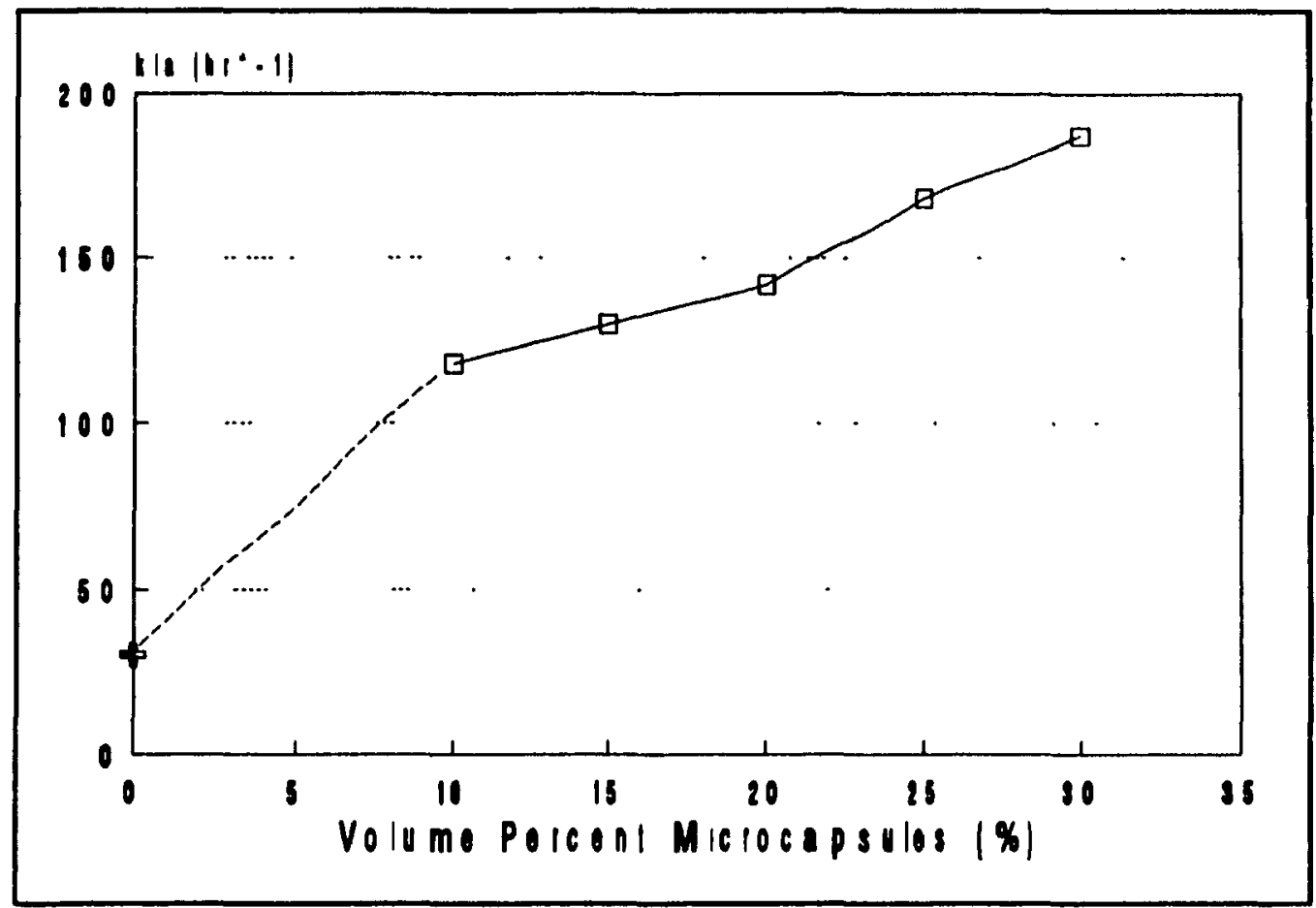

Figure 12. $\mathbf{k}_{\mathbf{L}}$ a Values versus Microcapsules Volume Fraction in Non-gerated System at $500 \mathrm{rpm}$ Agitation Speed

\subsubsection{Bubble Aerated System $-k_{L} a$ Measurement}

In the bubble-aerated system, the air flow rate was varied from $0.05 \mathrm{vvm}$ to $0.48 \mathrm{vvm}$ at $500 \mathrm{rpm}$, with and without microcapsules present. Figure 13 shows that for conventional bubble aeration, the $\mathrm{k}_{\mathrm{L}}$ a values increased with the air flow rate. In the presence of $20 \%(\mathrm{v} / \mathrm{v})$ microencapsulated silicone oils, the $k_{L}$ a values were enhanced following a similar trend. 


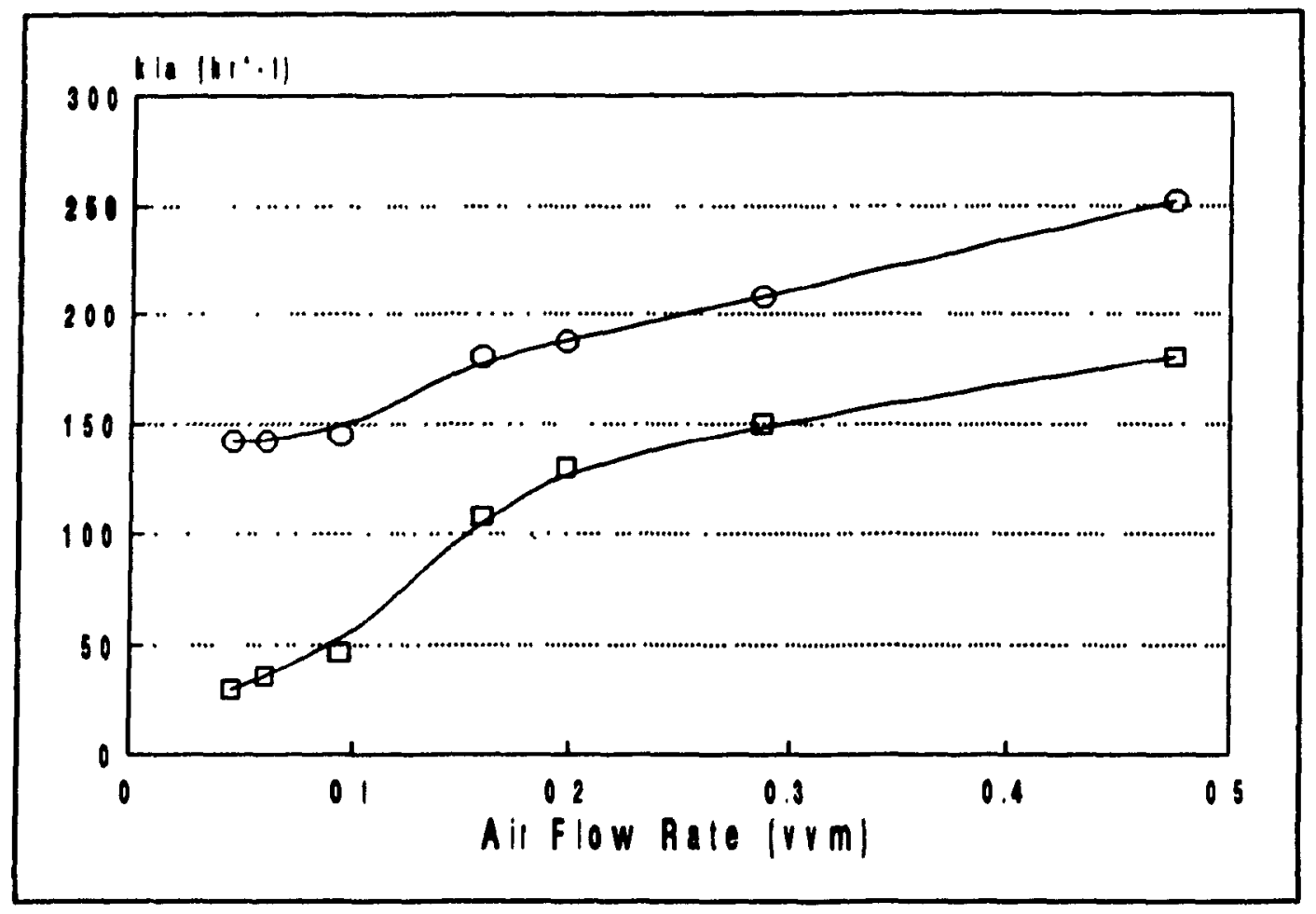

Figure 13. Variation of $k_{1} a$ with Air Flow Rate in the Presence of $20 \%$ silicone microcapsules $(O)$ or in the absence of microcapsules (D)

It can be seen that a high oxygen transfer coefficient $\left(\mathrm{k}_{\mathrm{L}} \mathrm{a}=180 \mathrm{hr}^{-1}\right)$ can be achieved in the conventional bubbling system at $0.48 \mathrm{vvm}$ air flow rate. However, at high mixing and aeration, shear-sensitive cells may not tolerate the shear. On the other hand, with $20 \%(\mathrm{v} / \mathrm{v})$ microcapsule suspension, the same oxygen transfer rate can be reached at $0.15 \mathrm{vvm}$ of air or less than $1 / 3$ that required with air alone. Therefore, oxygen carriers reduce the cost of aeration and the potential for cell damage due to the shear. The results also indicate that at very low aeration $(0.05 \mathrm{vvm})$ the $\mathrm{k}_{\mathrm{L}} \mathrm{a}$ was increased by a factor of 5 , due to 
poor oxygen transfer from bubbles, resulting in oxygenation from the microcapsules dominating. The $\mathrm{k}_{\mathrm{L}}$ a value of $145 \mathrm{hr}^{-1}$ is similar to that of the non-aerated system using $20 \%$ microcapsule suspension (figure. 12).

Figure 14 indicates that the oxygen transfer rate was also strongly influenced by the agitation speed. The $\mathrm{k}_{\mathrm{L}}$ a measurements were performed when three agitation speeds $(250,500,750 \mathrm{rpm})$ were compared at $0.3 \mathrm{vvm}$ air flow rate. As the rotational speed of the impeller increased, the oxygen transfer coefficient also increased. The presence of $20 \%(\mathrm{v} / \mathrm{v})$ microencapsulated silicone oil also enhanced the $k_{L} a$ values in a similar manner as the curve without microcapsules.

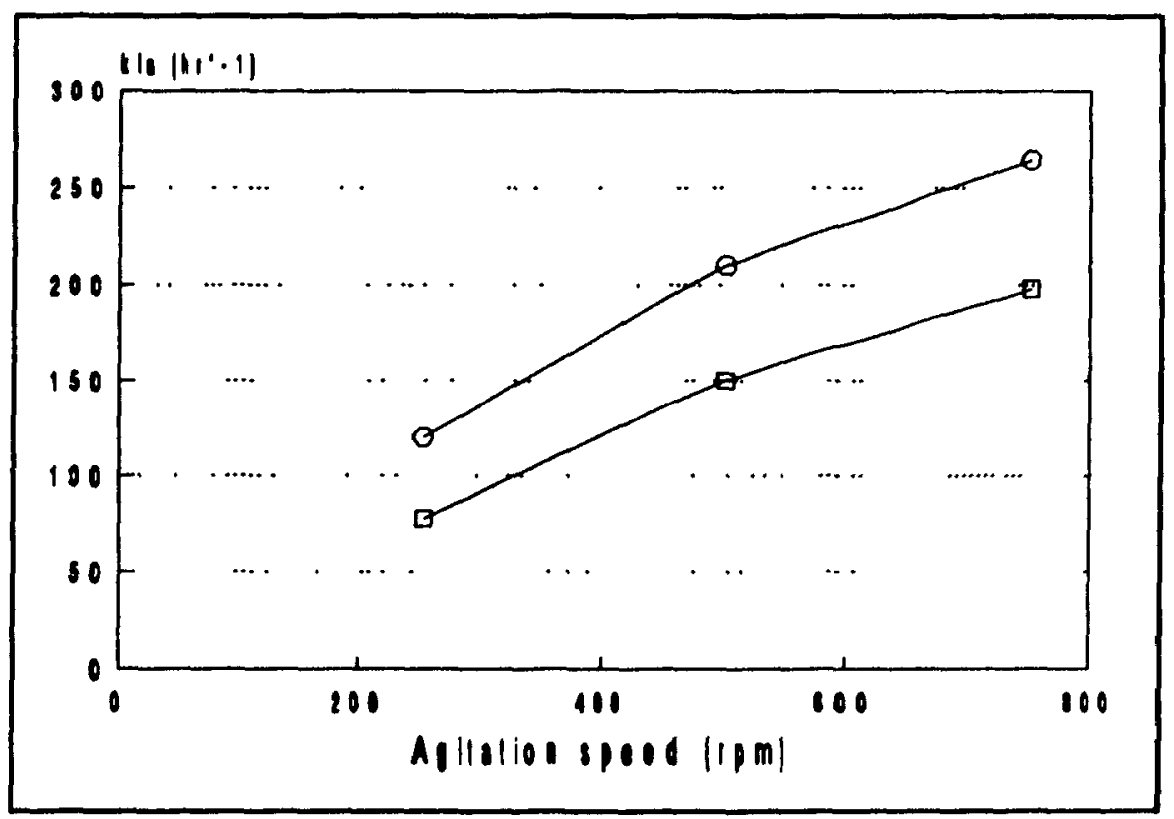

Figure 14. $k_{L^{a}}$ in Function of Agitation Speed with $20 \%$ microcapsules $(O)$ or with bubble aeration alone (D) 


\subsection{4 $k_{L}$ a Measurements with Cells}

$\mathrm{k}_{\mathrm{L}}$ a measurements were conducted to determine the oxygen transfer rate during the exponential phase of fermentation.

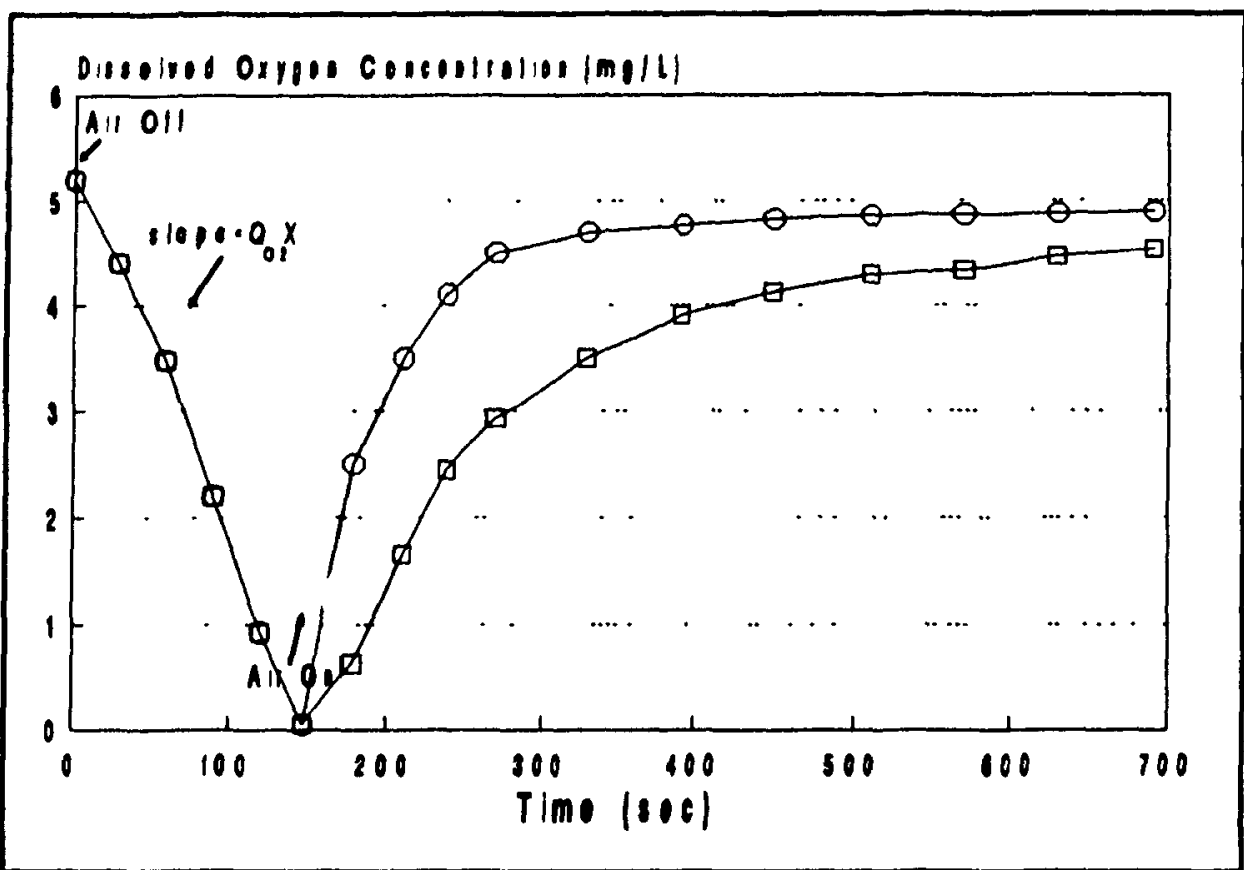

Figure 15. Dissolved Oxygen Concentration Profile During dynamic $k_{\mathbf{L}}$ a Measurement in 1.5L Fermentation with Ghconobacter suboxydans, with $20 \%(O)$ and without $(\square)$ microcapsules present

The oxygen uptake rate, $Q_{02} X$, was determined from figure 15 to be $4.6 \mathrm{mmol}$ $\mathrm{O}_{2} / \mathrm{L} / \mathrm{hr}$ and the specific oxygen uptake coefficient, $\mathrm{Q}_{\mathrm{O} 2}$, for Gluconobacter suboxydans during exponential phase was $19.3 \mathrm{mmol} \mathrm{O}_{2} / \mathrm{g}$ dry cell $/ \mathrm{hr}$. The rate of change in D.O. concentration in the fermenter is given by:

$$
\mathrm{dC}_{\mathrm{L}} / \mathrm{dt}=\mathrm{k}_{\mathrm{L}} \mathrm{a}\left(\mathrm{C}^{*}-\mathrm{C}_{\mathrm{L}}\right)-\mathrm{Q}_{\mathrm{O} 2} \mathrm{X}
$$


Thus, from plot of D.O. concentration $\left(C_{L}\right)$ in function of $\left(d C_{L} / d t+Q_{O 2}\right)$, the $1 / k_{L} a$ can be determined from the slope. The $k_{L} a$ for the control fermentation without microcapsules present was $34 \mathrm{hr}^{-1}$. In the presence of $20 \%(\mathrm{v} / \mathrm{v})$ microencapsulated silicone oil, the $\mathrm{k}_{\mathrm{L}}$ a was $135 \mathrm{hr}^{-1}$. Therefore, oxygen transfer capacities were increased by a factor of 4 using $20 \%$ microencapsulated silicone oils. These enhancements agreed with those obtained in the absence of cells (figure 13).

\subsection{Fermentation Results}

\subsubsection{Shake Flask Fermentation}

Gluconobacter oxydans was cultivated in standard medium containing $15 \%(v / v)$ silicone oil emulsion, or $15 \%(v / v)$ microencapsulated silicone oil. An inoculated control contained medium only. The dihydroxyacetone production rate of the shake flask cultures was monitored. Figure 16 indicates that both the non-encapsulated and encapsulated silicone oils enhanced the production rate by about $33 \%$ over that of the control culture. 


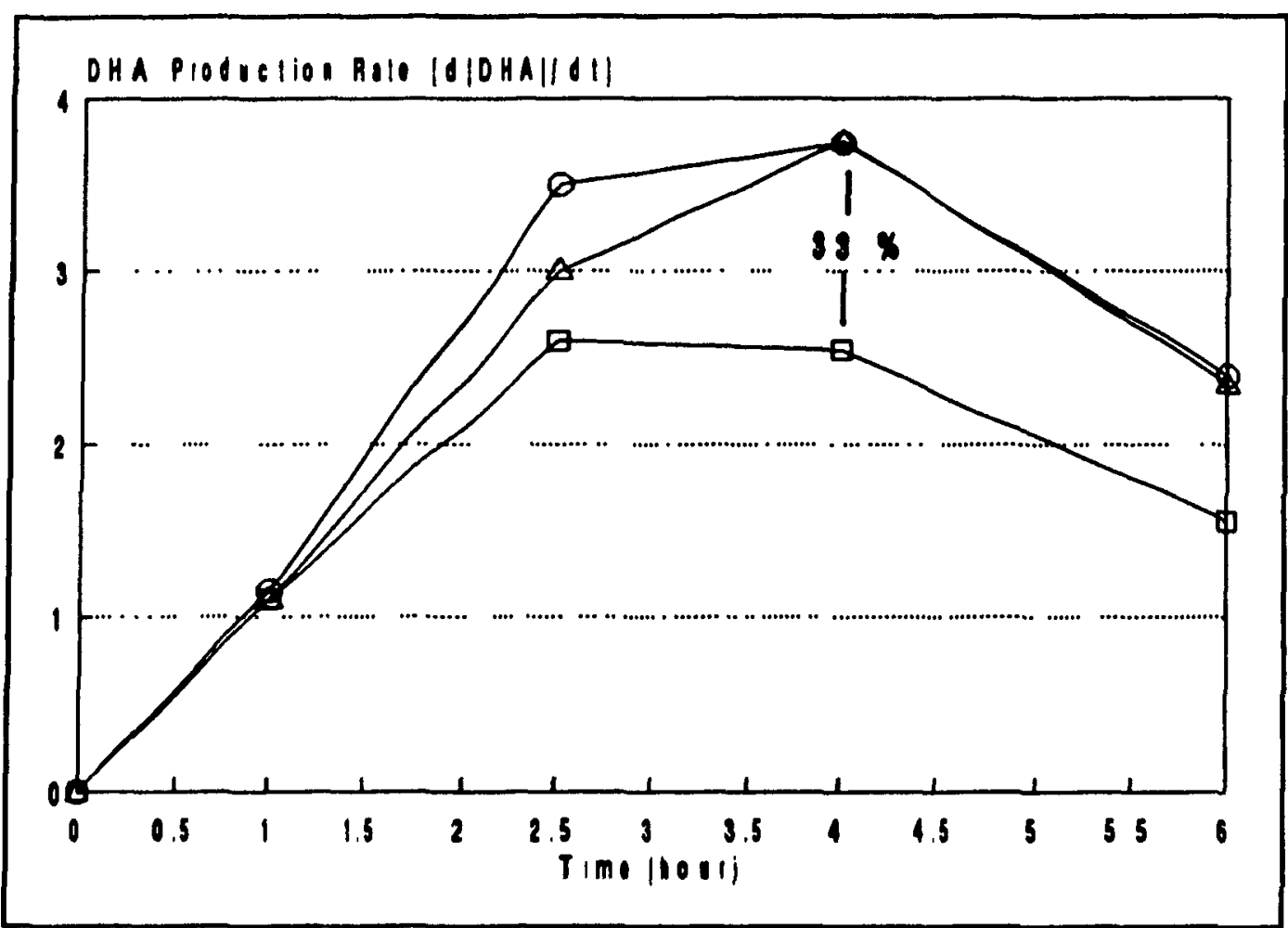

Figure 16. Shake Flask Fermentation with 15\% silicone oil ( $(\Delta)$ and $15 \%$ microencapsulated silicone oil (O) added. The control (D) experiment was conducted in the absence of oil.

\subsubsection{Batch Fermentation}

Figure 17. shows dissolved oxygen and DHA production rate profiles during two 1.5-litre Gluconobacter oxydans batch fermentations. One was a control fermentation with no microencapsulated silicone oils and the other contained $20 \%(\mathrm{v} / \mathrm{v})$ suspended microcapsules. Before the air was turned on at 1 hour, the production rate of dihydroxyacetone was zero. After air was 
supplied at $0.4 \mathrm{vvm}$ after 1 hour, the production rate for both fermentations increased to about $1 \mathrm{mM} \mathrm{DHA} / \mathrm{hr}$ and remained constant between 2 and 8.5 hours. In the control fermentation, the production rate increased gradually to $1.8 \mathrm{mM} \mathrm{DHA} / \mathrm{hr}$ between 8.5 to 15 hours. This increase was due to the exponential phase which began at approximately 6 hours. It can be seen that the D.O. concentration also decr ased drastically during the exponential phase. As the cell density was increasing, the D.O. concentration approached zero between 9 and 15 hours corresponding with the onset of oxygen-limited growth. During this period, the oxygen consumption rate exceeded the oxygen supply rate and oxygen became the limiting nutrient. Therefore, the production rate of DHA in the control fermentation increased only by 1.8 times during exponential growth. This poor productivity was also due to low oxygen transfer rate during exponential phase. The $\mathrm{k}_{\mathrm{L}}$ a was measured to be $34 \mathrm{hr}^{-1}$ (see 4.4.3). 

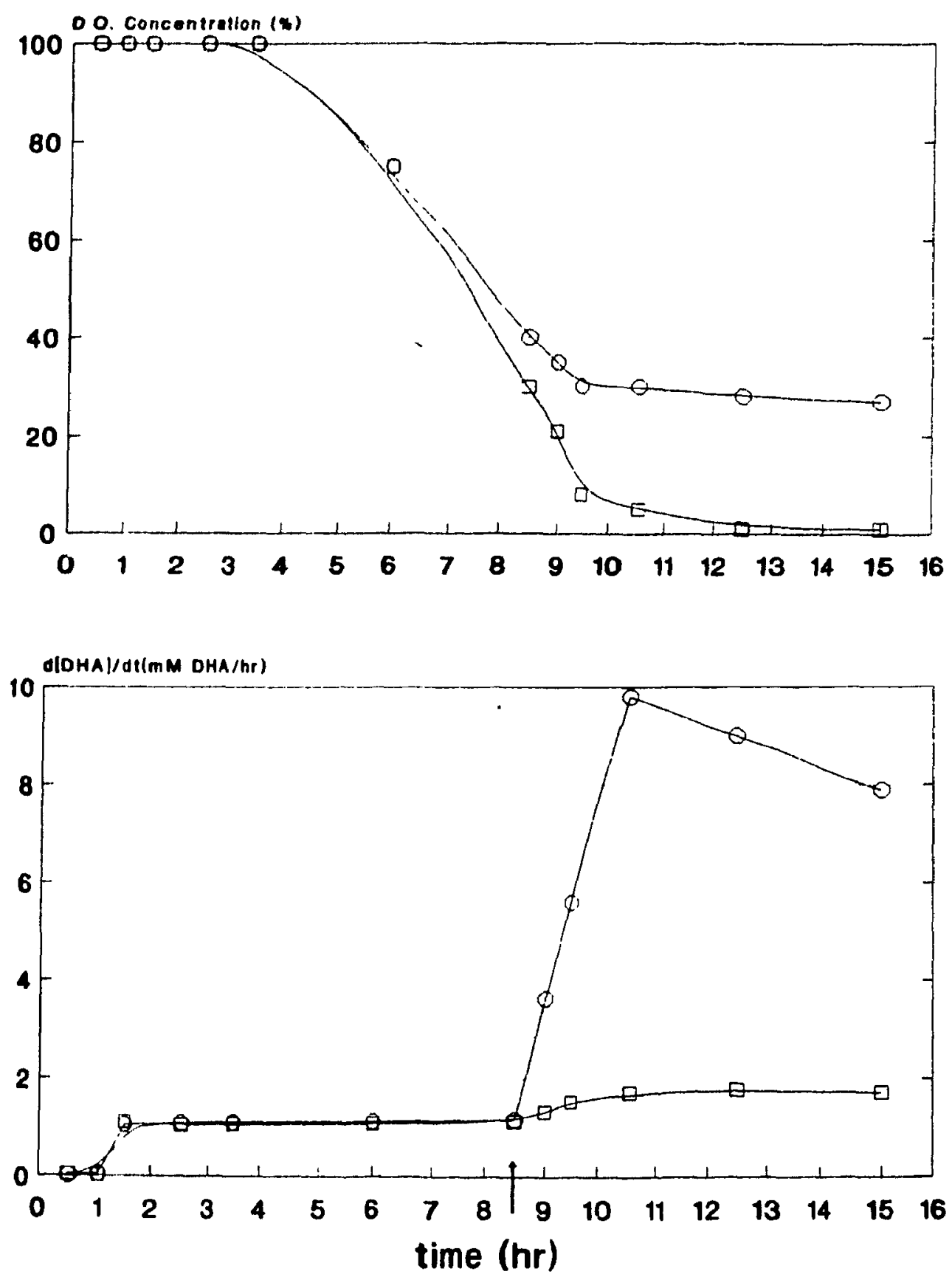

Figurc 17. Batch Fermentation of Ghronobacter suboxydans with $(O)$ and without ( $\square$ ) microencapsulated silicone oil in the culture medium. Rate of DHA production (fig. 17a) and dissolved oxygen concentration profiles (fig. 17b) are plotted. Microcapsules were added at 8.5 hour. 1.5-litre fermentations run at $0.3 \mathrm{vvm}$ air and $450 \mathrm{rpm}$ 
It was observed that the D.O. concentration remained at 30 to $40 \%$ saturation after the microencapsulated silicone oils $(20 \mathrm{v} / \mathrm{v} \%)$ were introduced at 8.5 hours. Thus, the addition of microcapsules before oxygen became limiting can avoid the oxygen limitation. Moreover, the $\mathrm{k}_{\mathrm{L}}$ a was measured to be $134 \mathrm{hr}^{-1}$ (see 4.4.3) after $20 \%$ of microcapsules were introduced to the fermentation broth. The four fold increase in oxygen transfer as well as the avoidance of oxygen-limited growth resulted in the increase of production rate of dihydroxyacetone from 1.5 to $9 \mathrm{mM} \mathrm{DHA} / \mathrm{hr}$.

\subsubsection{Fluidized Bed Fermentation}

In the fluidized bed fermentation, the microbial biomass was immobilized in calcium alginate gel beads which were suspended in an upward flow of nutrient medium. The flow rate was adjusted such that the upward drag of the liquid flow on the beads balanced the net weight of the beads. The amount of alginate beads used in the fermentation was $22 \mathrm{~g}$ (wet weight) and thus contained $800 \mathrm{mg}$ (dry weight) of Gluconobactersuboxydans. The alginate beads were then effectively suspended and uniformly distributed in the liquid. The top panel of figure 18 shows the dissolved oxygen profile at the reactor effluent during a fluidized bed fermentation. It is seen that the dissolved oxygen 
concentration was decreasing from saturation to almost $0 \%$ within 10 hours. After 10 hours, the oxygen consumption rate was higher than the oxygen supply rate, resulting in oxygen-limited growth. This ensuing period, between 10 and 12 hours, was characterized by the decreasing production rate of DHA shown in figure $18 \mathrm{~b}$. To ascertain that oxygen was supplied to the immobilized cells, a second oxygen electrode was placed at the feed of the reactor. The oxygen concentration in the feed remained at $100 \%$ throughout the entire fermentation.

At 12 hours, $20 \%(\mathrm{v} / \mathrm{v})$ of microencapsulated silicone oils were introduced to the fermentation. It was observed that the microcapsules were circulating freely in the reactor and the aeration section due to their small sizes (between 50 to $200 \mu \mathrm{m}$ ). The dissolved oxygen concentration increased to about $40 \%$ between 13 and 16 hours. The production rate of dihydroxyacetone also increased from 6 to $8 \mathrm{mM} \mathrm{DHA} / \mathrm{hr}$ after the addition of microcapsules. 

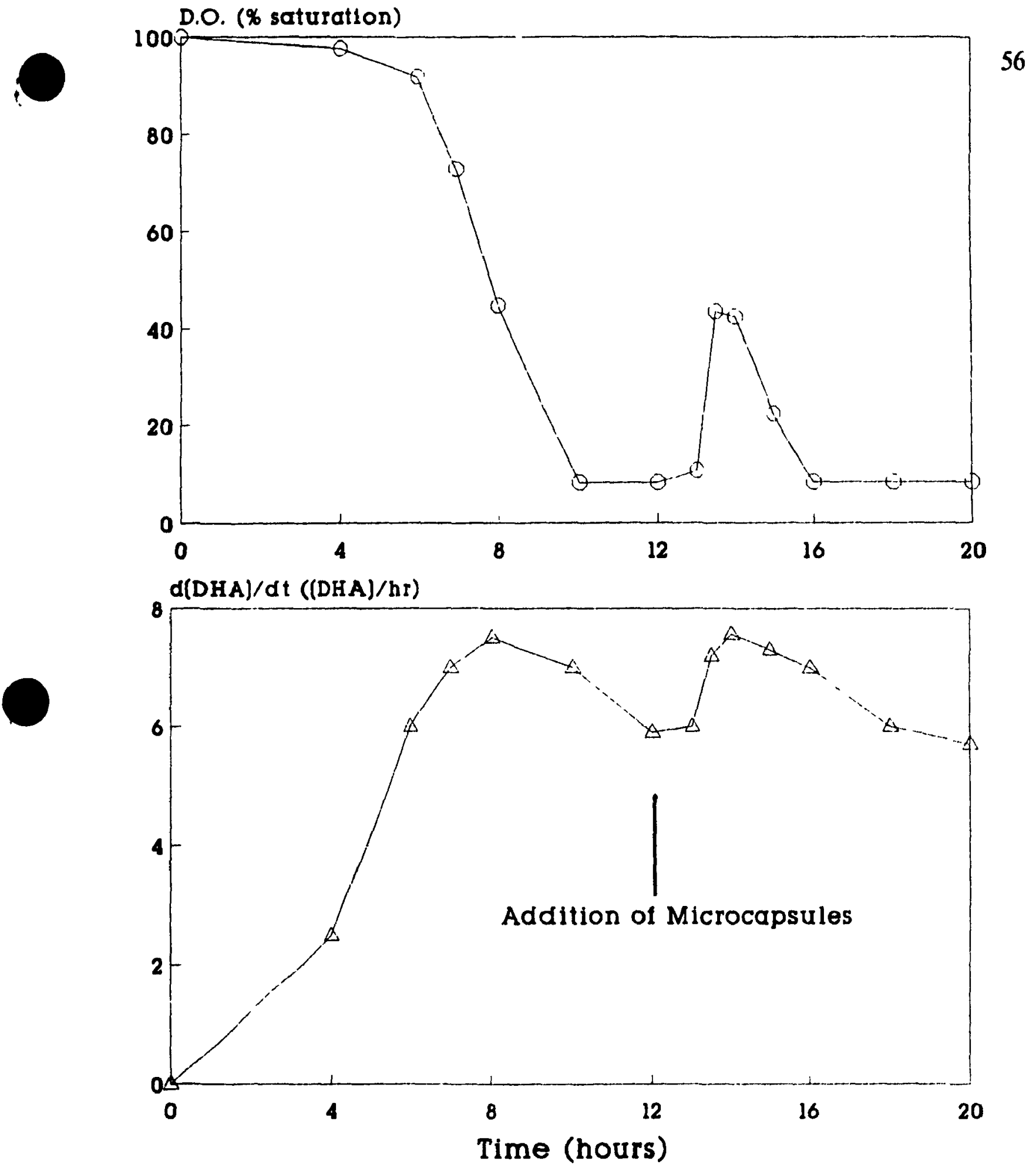

Figure 18 a) (top) Dissolved Oxygen Concentration versus Time in a Fluidized Bed Fermentation. b) (Bottom) Production Rate of Dihydroxyacetone versus Time in the Same Fluidized Bed Fermentation. The $20 \%(v / v)$ Microencapsulated Silicone Oils were Added at 12 hours. 


\subsection{DISCUSSION}

\subsection{Selection of an oxygen carrier.}

It appears that oxygen carriers may be divided into two classes as a function of the mechanism of oxygen fixation (figure 9). The oxygen concentration is directly proportional to the oxygen pressure for solvents which absorb oxygen. In contrast, chelation of oxygen by hemoglobin leads to a more complex relationship between oxygen concentration and pressure. The binding of four oxygens on hemoglobin results in a strong positive cooperative behavior leading to a sigmoidal oxygen saturation curve (Figure 9).

The concentration of oxygen in oxygenated red blood cells is double that of air and triple that of silicone at atmospheric pressure (Figure 9). Moreover, oxygen released from hemoglobin solution is accomplished within a small range of oxygen pressure. This oxygen binding/release behavior of hemoglobin may be of interest in the oxygenation of bioreactors due to its high oxygen capacity, and ability to maintain a constant oxygen pressure. However, hemoglobin is a chemically unstable molecule. Oxidation of methemoglobin inhibits the release of oxygen. The hemoglobin concentration is very high in red blood cells (around $300 \mathrm{~g} / 1$ ). Encapsulation of hemoglobin has been successful only at lower concentrations (less than $100 \mathrm{~g} / \mathrm{l}$ ). Moreover, the nylon encapsulating membranes are permeable to hemoglobin 
(unpublished data). Encapsulation itself denatures hemoglobin mainly by cross-linking of hemoglobin to the membrane during its formation. Finally, the pressure of oxygen during release is less than $4 \mathrm{kPa}$, too low for practical applications.

Air may be considered as a good oxygen carrier $(9.2 \mathrm{mM}$ at one atmosphere or $20 \mathrm{kPa}$ of oxygen, Figure 8) but due to the low oxygen transfer capabilities only a small part of this oxygen is really available to the cells in a typical bioreactor. Typical response times for conventional bubble aeration range from $30 \mathrm{~s}$ to $15 \min$ (i.e. $\mathrm{k}_{\mathrm{L}} \mathrm{a}=$ 4 to $\left.120 \mathrm{hr}^{-1}\right)^{8}$.

Oxygen is soluble at high levels (4 to $6 \mathrm{mM}$ ) in many organic solvents and solvent-water oxygen exchange has proven to be faster than in air-water systems ${ }^{10.15,41}$. Silicones and perfluorocarbons represent the highest affinity for oxygen, yet only one third that of red blood cells in contact with air. However, when the oxygen pressure exceeds $15 \mathrm{kPa}$, the oxygen concentration in red blood cells remains constant, but is proportional to the oxygen pressure with silicone and other oxygen absorbents. If economically feasible, use of pure oxygen would lead to a concentration of $30 \mathrm{mM}$ in silicone, higher than what may be expected from concentrated hemoglobin solutions. It is also important for the oxygen carriers to carry other gases, for example, carbon dioxide. This gas is often produced in aerobic bioprocesses and is inhibitory to many organisms. Therefore, it would be ideal if the oxygen carriers can transfer the 
reaction-promoting gas to the reactor while absorbing the inhibitory gases.

Besides the high capacity for oxygen and the inhibitory gases, desirable characteristics that were sought when selecting suitable oxygen carriers included a low toxicity to biological cells, stability for extended periods and low-volatility. The carrier must either be water insoluble or have a high molecular weight, to maintain the compound within the encapsulating membranes to facilitate recovery and recycle.

Based on these criteria, silicone oils and perfluorocarbon chemicals are the most suitable oxygen carriers. However, for many engineering applications such as oxygenation of potable water, or wastewaters in purification operations, low cost of the material is a priority. Silicone oils ( $10 \mathrm{cs}$ ) are about 50 to $60 \%$ the cost of most PFC's, therefore, were selected in the present study.

\subsection{Microencapsulation Of Oxygen Carriers}

The low reactivity of silicone oils enables use of interfacial polymerization with diamine and dichloride to form polyamide (nylon) membranes. Nylon membranes are very thin $(200 \mathrm{~nm})$ in comparison to other types of membranes such as collodion $(3 \mathrm{\mu m})$, thus, enhancing oxygen transfer. The addition of a preformed branched polymer may result in stronger membranes. In the present study, addition of $2 \%(\mathrm{v} / \mathrm{v})$ polyethylenimine to the diamine solution yields resistant membranes. In order to make 
a process economical, recycle of the microcapsules is a key factor. Moreover, since most of the fermentation processes are lengthy and the medium is constantly under high mixing, the strength of the membranes plays a very important role. These microcapsules are proven to be shear resistant over time as well as steam autoclavable without breakage. In addition, due to the low density of silicone oils, the microcapsules can be easily recovered (e.g. flotation)

The use of 1 cs silicone resulted in stronger microcapsules, but due to its volatility, slight water solubility and cost (ten times the cost of $10 \mathrm{cs}), 10 \mathrm{cs}$ silicone was preferred. To achieve a narrow size distribution, the discontinuous and continuous phases during emulsification should havesimilar viscosities and densities. The different characteristics of microcapsules with silicones of increasing viscosity may be related to decreasing solubility of the acid dichloride.

\subsection{Oxygenation Capacity by Microencapsulated Silicone Oils}

\subsubsection{Oxygenation Capacity by Microencapsulated Silicone Oils versus}

\section{Non-bubbling Systems}

Oxygen solubility in silicone microcapsules is approximately $6 \mathrm{mM}$ compared to $0.3 \mathrm{mM}$ for water (i.e. 20 times higher). Assuming that the microcapsules represent 10 to $20 \%$ of the reactor volume, the oxygen reservoir is 
multiplied by a factor of 4 to 7 (Figure 19). If the microcapsules $(20 \%)$ were re-generated with pure oxygen, the oxygen reservoir will increase by a factor of up to 30 (Figure 19).

\section{Relative Amount of Oxyoen Available in Bioreactor}

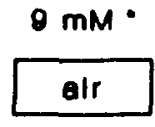

$0 \times m$ c.

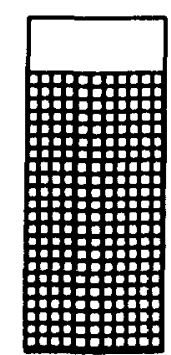

$0.22 \mathrm{mmol}$

[1]
$6 \mathrm{mM}$

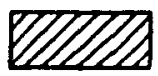

$10 \% \mathrm{~m} \mathrm{c}$

(8at. AIR)

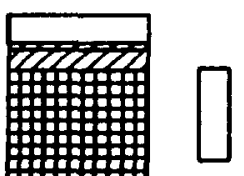

$82 \mathrm{mmol}$

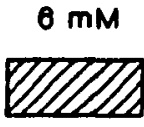

$20 \%$ m.c.

(sot. AIR)

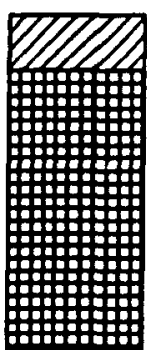

$1.42 \mathrm{mmol}$
$30 \mathrm{mM}$

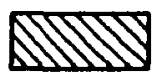

20 \& m.c.

(88t. $O_{2}$ )

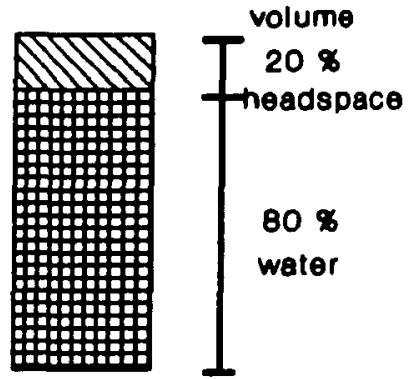

$0.22 \mathrm{mmol}$

\section{[6.5] \\ [28.3]}

-Aseumpllon: Oxyeen Irom headepace le not evallable 10 celle

Figure 19. Relative amount of oxygen available to cells in bioreactor containing different concentration of microencapsulated oxygen carrier

Bioreactors for shear sensitive cell cultures (mammalian and plant cells) may supply oxygen in the influent or the recirculation loop. The maximum oxygen concentration in the fluid is then limited to $0.3 \mathrm{mM}$ (oxygen water saturation). 
Using a $10 \% \mathrm{v}$ (or $20 \% \mathrm{v}$ ) microcapsule suspension as influent yields $0.9 \mathrm{mM}$ (respectively $1.5 \mathrm{mM}$ ) in oxygen. Moreover, the flow of liquid and microcapsules may be independent. By adjusting the density of the capsules, their residence time in the reactor may be shorter than the residence time of the liquid. The microcapsules may then he recirculated at higher concentration (up to $50 \%$ ) while maintaining their concentration at a low level in the reactor (around $20 \%$ ). The oxygen concentration in the high loaded microcapsule influent may then reach 3.3 $\mathrm{mM}$ to be compared with $0.3 \mathrm{mM}$ for oxygen saturated water recirculation. If pure oxygen is used for the microcapsule reaeration, the concentration of oxygen may even be increased by a factor approaching 50 . Taking into account this high concentration, one may reduce the recirculation flow while increasing the oxygen supply to the reactor, improving the efficiency of reaeration. The use of pure oxygen may then become economically and technically feasible.

In this specific case, the performance that may be reached with encapsulated oxygen carriers may be compared with that obtained with non-encapsulated oxygen carriers $1,2,3,4$. Using air for re-aeration, bioreactor performance was increased by a factor of 4 to $5^{25}$. A similar performance may be expected when using microcapsules but the encapsulation of the oxygen carries facilitates the control of the permanent dispersion without the need for a surfactant ${ }^{35}$. The 
membrane may also reduce potential toxic effects observed with perfluorocarbons on cells ${ }^{10}$.

\subsubsection{Oxygenation Capacity by Microencapsulated Silicone Oils versus}

\section{Bubbling Systems}

The residence time of a bubble in a bioreactor is short and difficult to control. Generally, the time is insufficient to release all the oxygen. Increasing gas flow through a reactor generally results in an increase of the bubble diameter (from 1 to a few millimeters in large scale reactor), and decrease in the bubble surface area per volume, and the residence time. Oxygen transfer capabilities are then not directly related to the gas flow rate. On the other hand, the microcapsule residence time may be optimized to increase the oxygen transfer efficiency maintaining a high concentration of oxygen. Moreover, the diameter of the microcapsules is independent of gas flow rate. Thus, the microcapsule surface area per volume is easier to manipulate than that of air bubbles. 


\subsubsection{Oxygenation Capacity by Microencapsulated Silicone Oils in Viscous}

\section{Media}

When the culture media is viscous at elevated cell concentrations, it is difficult for bubbles or microcapsules to pass through the reactor. Oxygen may be supplied by diffusion through a membrane or a grid. The resilence time of the bubble in a column is short ( $4 \mathrm{~s} / \mathrm{m}$ height) ${ }^{31}$. Comparing this short time to the response time of oxygen release from bubbles, it may be concluded that only a fraction of the oxygen is transferred to the medium (less than $10 \% / \mathrm{m}$ height). Use of microcapsules permits the optimization of the residence time of the oxygen carrier in the column. Use of microcapsules will then allow the operator to maximize the oxygen concentration in the column while reducing the cost.

\subsection{Oxygen Transfer Rate Enhancement using Microencapsulated Silicone Oils}

Figure 12 shows that the oxygen transfer coefficient, $\mathrm{k}_{\mathrm{L}} \mathrm{a}$, for the microcapsuleto-water was $187 \mathrm{hr}^{-1}$ using $30 \%(\mathrm{v} / \mathrm{v})$ microcapsules in the non-bubbling system. This is equivalent to the $\mathrm{k}_{\mathrm{L}}$ a value obtained using $0.5 \mathrm{vvm}$ air flow rate for the conventional bubbling system at the same agitation (fig 13). This suggests that $30 \%(\mathrm{v} / \mathrm{v})$ microcapsules may generate an equivalent oxygen transfer capacity as if using $0.5 \mathrm{vvm}$ of aeration under similar same conditions. Therefore, the microencapsulated oxygen 
carriers not only increase the oxygen reservoir but also the transfer rates in nonbubbling systems. Furthermore, the $\mathrm{k}_{\mathrm{L}}$ a values increased linearly from 125 to $187 \mathrm{hr}^{-1}$ when the microcapsules were increased from 10 to $30 \%(\mathrm{v} / \mathrm{v})$. Goma et al. ${ }^{17}$ also demonstrated a similar relationship between the volume fractions of oxygen carriers and the $\mathrm{k}_{\mathrm{L}} \mathrm{a}$ values.

In the agitation-aeration conditions, it can be seen from both figures 13 and 14 that $20 \%(\mathrm{v} / \mathrm{v})$ microcapsules enhanced oxygen transfer coefficients by a factor of 1.5 to 5 depending on the conditions. In the presence of cells, . imilar enhancement of oxygen transfer was observed (figure 15). The $\mathrm{k}_{\mathrm{L}}$ a obtained using $20 \%(\mathrm{v} / \mathrm{v})$ microcapsules ranged from 120 to $258 \mathrm{hr}^{-1}$ (figure 12, 13, and 14) which are higher compared to those observed in conventional bubbling systems. A value less than $120 \mathrm{hr}^{-1}$ was reported with intense mixing, and less than $4 \mathrm{hr}^{-1}$ under poor mixing conditions $^{8}$.

The high oxygen transfer coefficient for the release of oxygen from microcapsules may be attributed to the small diameter ( 50 to $150 \mu \mathrm{m}$ ) compared to that of air bubbles (few millimeters in large scale reactors ${ }^{8}$ or $1.5 \mathrm{~mm}$ in perfluorocarbon chemical dispersions ${ }^{47}$ ). Furlue muie, both McMillan et al ${ }^{47}$ and Goma et al ${ }^{17}$ showed that exchange through the gas-liquid interface is slower than through liquid-liquid interfaces. This implies that the resistance to oxygen transfer of the oxygen-carrier-water system 
is located in the water boundary layer. Taking into account both the increase of specific surface area (inversely proportional to particle diameter) and the increase of the transfer coefficient $\left(k_{L}\right)^{23}$, oxygen transfer rates from microcapsules would be faster than an efficient bubbling systems under high mixing.

The nylon membrane did not appear to reduce the diffusion rate of oxygen from the microcapsules. Nylon membranes contain up to $85 \%$ water and the pore sizes are large, permitting diffusion of molecules as large as hemoglobin. Concer ning mo'ecular oxygen, the nylon membrane appears more like a grid with large openings than a real barrier to mass transfer.

\subsection{Comparison of Oxygen Transfer Performance between Microencapsulated}

\section{Silicone Oils and other Oxygen Carriers}

In the past two decades, almost all the research on oxygen carriers was focussed on perfluorocarbon chemicals ${ }^{3,10,27,47}$, (e.g. FC-43, FC-72) and hydrocarbons ${ }^{17,18}$ (e.g. ndodecane). Only a few reseachers have reported the use of silicone oils ${ }^{11,25}$. However, it is shown in Table 3 that the solubility of silicone oils is higher than many other oxygen carriers. Moreover, the enhancements of oxygen transfer capacity were found to be increased 3.5 times using 10 to $30 \%$ n-dodecane (Goma ${ }^{15}$ ), and 4 times using $40 \%$ PFC (Wang ${ }^{43}$ ). However, most of the PFC emulsions are stabilized with surfactants 
(e.g. Pluronic $\mathrm{F}-68^{3}$ ), mechanical agitation or ultrasonic treatment. The surfactant was found to be toxic to certain types of microorganisms ${ }^{10}$ and ultrasonic treatment and intense mixing may cause shear damage to the cells. On the other hand, microencapsulated silicone oils do not require the addition of surfactant or other forms of treatment to disperse and stabilize the oxygen carriers. The $\mathrm{k}_{\mathrm{L}} \mathrm{a}$ was observed to be higher than that obtained from other oxygen carrier dispersions. Therefore, the silicone microcapsules are more biocompatible than PFC's or other pure organic solvents while the oxygen transfer capacity is competitive.

\subsection{Fermentation $R$ ssults}

\subsubsection{Batch Fermentation}

The experimental work was undertaken with Gluconobacter oxydans. This strain was chosen due to its high demand for oxygen and high sensitivity to the amount of dissolved oxygen ${ }^{6,7}$. In the shake flask fermentation, the amount of oxygen available to the cells was limited since the main oxygen source was from surface aeration. Therefore, the oxygen became the limiting nutrient. After $20 \%$ (v/v) of aerated, encapsulated or non-encapsulated, silicone oils were introduced to the medium, the amount of oxygen available became 6.5 times higher (fig. 19) than the reference culture without silicone oils. Furthermore, the oxygen transfer 
capacities increased dramatically when cultivation was carried out in microcapsulein-water dispersions. Therefore, the productivity was expected to be improved. As shown in figure 16, both encapsulated and non-encapsulated silicone oils enhanced the production rate of dihydroxyacetone by $33 \%$. This increase was not as high as expected due to the limited oxygen transfer in the flask compared to a well-agitated fermenter with sufficient aeration. However, it demonstrates that silicone oils in either encapsulated or non-capsulated form improve the productivity. This also indicates that the nylon membrane is not a barrier to oxygen transfer.

In the 1.5-litre batch fermentation, the productivity enhancements were more noticeable. The measured $\mathrm{k}_{\mathrm{L}}$ a during exponential phase was $34 \mathrm{hr}^{-1}$. Therefore, growth would be limited by the weak oxygen transfer even though the system was under agitation and aeration. As shown in figure 17, the dissolved oxygen profile shows that the D.O. level remained low during the exponential growth phase. However, after the microencapsulated silicone oils were introduced in the medium, the D.O. level remained at $30 \%$ saturation compared to oxygen depletion in the reference culture. Therefore, the oxygen limitation was total avoided by the addition of microcapsules. This indicates that the oxygen carriers act as the oxygen reservoir.

The $\mathrm{k}_{\mathrm{L}}$ a was measured to be about 4 to 5 times higher after the addition of 
microcapsules with or without the presence of cells (figure 13 and 15). In the batch fermentation, improved oxygen transfer capacity and the removal of oxygen limitation translated into greater productivity. The production rate increased by a factor of 5 (figure 15). Toxic effects or inhibition were not observed in the course of fermentation. Therefore, the microencapsulation technique avoids the toxic effects as well as maintaining the high oxygen transfer capacity. Overall, observed increases in productivity indicates that a small fraction of microencapsulated silicone oils suspended in fermentation broth may potentially increase revenues per unit reactor per unit time.

\subsubsection{Fluidized Bed Fermentation}

In conventional fluidized bed fermentations, the principal problem is often to maintain sufficient oxygen supply. Sparging gas into a liquid fluidized bed reduces the effective liquid density and the fluidized particles settle more rapidly ${ }^{48}$. Pre-dissolved air in the liquid feed provides sufficient oxygen for only a short period of fermentation due to the low oxygen solubility in water ${ }^{48}$. In this study, there was no direct bubbling to the reactor, the oxygen availability was determined solely by the feed. As seen in figure 18, the oxygen-limited growth period began after 8 hours, concomitant with a decrease in the production rate of DHA. The introduction of 
$20 \%(\mathrm{v} / \mathrm{v})$ microcapsules at 12 hours enhanced the oxygen saturation from 0 to $40 \%$, due to the high oxygen solubility in the microcapsules $(6 \mathrm{mM})$ compared to water $(0.3 \mathrm{mM})$.

The specific oxygen uptake rate of the bacteria was 19.3 mmole $\mathrm{O}_{2} / \mathrm{g}$ dry cell/hr and thus the oxygen uptake rate during the exponential phase was at least 15.4 mmole/hr. Without microencapsulated silicone oils, the oxygen saturated feed stream provided only $0.03 \mathrm{mmole} / \mathrm{min}(1.8 \mathrm{mmole} / \mathrm{hr})$ to the reactor at a liquid flow rate of $100 \mathrm{ml} / \mathrm{min}$ ). This was insufficient to satisfy the high oxygen demand from the cells and therefore the productivity decreased as cxygen-limited growth began. Using $20 \%$ microencapsulated silicone oils as influent yielded $1.5 \mathrm{mM}$ of oxygen concentration which was 5 times higher than liquid medium alone. This enhancement in oxygen capacity was translatable to enhancement in fermentation productivity. 


\subsection{CONCLUSIONS}

Silicone oils as oxygen carriers were successfully microencapsulated within nylon membranes cross-linked with polyethylenimine. The microencapsulated oxygen carriers (e.g. $20 \% \mathrm{v} / \mathrm{v}$ ) increase the oxygen reservoir by a factor of 7 as well as the oxygen transfer rates by a factor of 5 in comparison to conventional bubble aeration. Enhancement in the oxygen supply to bioreactors may result in an improvement of bioreactor productivity in systems with shear sensitive cell lines or with high oxygen demand. The oxygen permeable polymeric membrane coating the oxygen carrier should reduce toxic or inhibitory effects previously observed during use with live cells. 


\subsection{NOMENCLATURE}

a interfacial area per unit volume of dispersion, $\mathrm{cm}^{2} / \mathrm{cm}^{3}$

$C^{*}$ saturation concentration of dissolved oxygen at bubble surface, $\mathrm{mol} / \mathrm{L}$

$\mathrm{C}_{\mathrm{L}}$ bulk concentration of dissolved oxygen, $\mathrm{mol} / \mathrm{L}$

$\mathrm{C}_{\mathrm{LO}} \quad$ D.O. concentration at $\mathrm{t}=0, \mathrm{~mol} / \mathrm{L}$

H Henry Law constant of the fermentation medium, mol/l-atm

$k_{\mathrm{L}} \quad$ liquid phase oxygen transfer coefficient, $\mathrm{cm} / \mathrm{s}$

$\mathbf{K}_{\mathrm{p}} \quad$ probe constant, $\mathbf{s}_{-1}$

$p_{0} \quad$ oxygen partial pressure of the exhaust gas, atm

$\mathrm{Q}_{\mathrm{O} 2} \quad$ specific rate of Oxygen consumption, mole/g/hr

$\mathrm{X} \quad$ biomass concentration, $\mathrm{g} / 1$

$Y_{P} \quad$ normalized probe response

$\mathrm{Y}_{\mathrm{L}} \quad$ normalized oxygen concentration in liquid phase,

$\mathrm{T}_{\mathrm{p}} \quad$ probe time constant, $\mathrm{s}$

$\alpha_{e} \quad$ the area above the chart of the transient aeration experiment,

$\alpha_{s} \quad$ the area above the recorder chart of the electrode step response experiment 


\subsection{REFERENCES:}

1. ADLERCREUTZ,P., and MATTIASSON, B., "Oxygen Supply to immobilized cells: 1-oxygen production by immobilized Chlorella pyrenoidosa", Enzyme Micob. Technol.,4. 332-336 (1982).

2. ADLERCREUTZ, P., and MATTIASSON, B., "Oxygen Supply to immobilized cells: 2-Studies on a Coimmobilized Algae-Bacteria Preparation with in situ Oxygen Generation ", Enzyme Micob. Technol.,44. 395-400 (1982).

3. ADLERCREUTZ, P., and MATTIASSON, B., "Oxygen Supply to immobilized cells: 3-Oxygen Supply by Haemoglobin or Emulsions of Perfluorochemicals", Appl. Microbiol. Biotech., 16, p165-170 (1982).

4. ADLERCREUTZ, P., and MATTIASSON, B., "Oxygen Supply to immobilized cells: 4-Use of p-benzoquinone as an Oxygen Substitute", Appl. Microbiol. Biotech., 20, p296-302 (1984).

5. ADLERCREUTZ, P., "Oxygen Supply to immobilized cells: 5-Theoretical Calculations and Experimental Data for the Oxidation of Glycerol by Immobilized Gluconobacter oxydans Cells with Oxygen or p-Benzoquinone as Electron Acceptor", Biotech. and Bioeng., 28, p224-232 (1986)

6. ADLERCREUTZ, P., and MATTIASSON, B., "Perfluorochemicals in Biotechnology", TIBTECH, 5, p250-254 (Sep. 1987).

7. ADLERCREUTZ, P., MATTIASSON, B., and HOLST, O., "Characterization of Gluconobacter oxydans Immobilized in Calcium Alginate", Appl. Microbiol. Biotech., 22, pl-7 (1985)

8. ATKINSON, B., FERDA M., Biochemical Engineering and Biotechnology Handbook, p772, Macmillan, Surrey, England (1983).

9. BORIES, A., ClARET, C., SOUCAILlE, P., "Kineic Study and Optimisation of Prodiction of Dihydroxyacetone from Glycerol using Gluconobacter oxydans", Process Biochemistry, 26, p243-248 (1991). 
10. CHANDLER, D., DAVEY, M.R., LOWE, K.C., and MULLIGAN, B.J , "Effexts of Emulsified Perfluorochemicals on Growth and Ultrastructure of Microbial Cells in Culture", Biotech. Letters, 2No.3, p195-200 (1987).

11. CHIBATA et al, "Cultivation of Aerobic Microorganisms", US patent $\$ .3,850,75$. , (Nov 1974)

12. DAVIS, S.S., WASHINGTON, C., and JOHNSON, O.L., "Thermal Stability of Fluorocarbon Emulsions that Transport Oxygen", Internat. Journ. of Pharm., 59, p131135 (1990).

13. DAMIANO, D.S., "Novel Use of a Perfluorocarbon for Supplying Oxygen to Aerobic Submerged Cultures", Biotech. Letter, 1, p82 (1985).

14. FUJITA, M., HASHIMOTO, S., Journal Fermentation Technology, 48, p461

15. GEYER, R.P., "Perfluorochemicals as Oxygen Transport Vechicles", Biomat., Art. Cells, Art. Org., 16(1-3), p31-49 (1988).

16. GEYER, R.P., "Perfluorochemicals as Biological Oxygen Carriers", Progress in Artifical Organs (1985).

17. GOMA, G., ROLS, J.L., CONDORET, J.S., and FONADE, C., " Mechanism of Enchanced Oxygen Transfer in Fermentation Using Emulsified Oxygen-Vectors", Biotech. and Bioeng., 35, p427-435 (1990).

18. GOMA, G.,and ROLS, J.L., "Enhancement of Oxygen Transfer Rates in Fermentation using Oxygen-Vectors", Biotech. Adv, Z, p1-14 (1984).

19. HAMAMOTO, K., TOKASHIKI, M., ICHIKAWA, Y., and MURAKAMI, H., "High Cell Density Culture of a Hybridoma Using Perfluorocarbon to Supply Oxygen", Agric. Bio. Chem., 51 (12), p3415-3416 (1987).

20. HERTL et al, Means for Stimulating Microbial Growth, US patent \#4, 166,006, (Aug 1979)

21. HO, C.S., and JU, L.K., "Oxygen Diffusion Coefficient and Solubility in n-Hexadecane", Biotech. and Bioeng., 34, p1221-1224 (1989). 
22. HOLST, O., MATTIASSON, B., ENFORS, S.O., "Oxygenation of Immobilized Cells Using Hydrogen-Peroxide; A Model Study of Gluconobacter oxydans Converting Glycerol to Dihydroxyacetone" , European J Appl Microbiol Biotechnol, 14, 64-68 (1982).

23. JOHNSON, M., ANDRE, G., CHAVARIE, C., and ARCHAMBAULT, J., "Oxygen Transfer Rates in a Mammalian Cell Culture Bioreactor Equipped with a Cell-Lift Impeller", Biotech. and Bioeng., 35, p43-49 (1990).

24. KLEI, H. E., and SUNDSTROM D.W., "Immobilization of enzymes by Microencapsulation" in Immobilised Cells and Enzymes-a Practical Approach, p49--54

25. LEONHARDT, A., SZWAJCER, E., and MOSBACH, K., "The Potential Use of Silicon Compounds as Oxygen Carriers for Free and Immobilized cells containing L-amino Acid Oxidase", Appl. Microbiol. Biotech., 21, p162-166 (1985).

26. LINEK, V., BENES, P., and VACEK, V., "Dynamic Pressure Method for $\mathrm{k}_{\mathrm{L}} \mathrm{a}$, Measurement in Large-Scale Bioreactors", Biotech. and Bioeng., 33, p1406-1412 (1989).

27. LOWE, K.C., "Perfluorocarbons as Oxygen-Transport Fluids", Comp. Biochem. Physiol., 87A, p825-838 (1987).

28. LOWE, K.C., KING, A.T., and MULLIGAN, B.J., "Perfluorochemicals and Cell Culture", Biotech., 7,(1989).

29. MILLER, G.L., BLUM, R., GLENNON, W.E., and BURTON, A.L., "Measurements of Carboxymethylcellulase Activity", Anal. Biochem., 2, p127-132 (1960).

30. MOORE, R.E., "Physical Properties of a New Synthetic Oxygen Carriers", Biomat. Art. Cells, Art. Org., 16(1-3), p443-445 (1988).

31. PAUSS , A., ANDRE, G., GUIOT, S.,PERRIER, M., "Liquid to Gas Mass Transfer in Anaerobic Processes: Inevitable Transfer Limitation of Methane and Hydrogen in the Biomethanisation Process", App. Env. Microbiol. 56: p1636 (1990)

32. PONCELET, D., , CENTOMO, L., LEUNG, R. NEUFELD, R.J.,"Microencapsulated Sllicone Oils for Bioreactor Oxygenation", Biotech. and Bioeng. (IN PRESS 1992) 
33. PONCELET, D., NEUFELD, R. J. "Shear Breakage of Nylon Membrane Microcapsules in a Turbine Reactor", Biotechnol. bioeng. XXXIU: p95. (1989)

34. PONCELET, D., PONCELET De SMET, B., NEUFELD, R. J. "Mass Transfer in Nylon Membrane Bound Microcapsules", 38th Can. Chem. Eng. Conf., Oct. 2-5, 1988, Edmonton, Canada

35. PONCELET De SMET, B., PONCELET, D., NEUFELD, R. J. "Control of Mean Diameter and Size Distribution during Formulation of Microcapsules with Cellulose Nitrate Membranes", Enz. Microb. Technol. 11 p29. (1989)

36. SCHLEGEL, H.G., "Aeration without Air: Oxygen Supply by Hydrogen Peroxide", Biotech. and Bioeng., 19, p413-424 (1977).

37. SCHLEGEL, H.G., and IBRAHIM, H.G., "Oxygen Supply to Bacterial Suspensions of High Cell Densities by Hydrogen Peroxide", Biotech. and Bioeng., 22, p18771894 (1980).

38. SOBOTKA, M., PROKOP, A., DUNN, I.J., "Review of Methods for the Measurement of Oxygen Transfer in Microbial System" Annual Reports on Fermentation Processs, Vol. 5, p127-210 Academic Press (1982).

39. TANAKA, H., ISHIKAWA, H., OSUSA, K., and TAKAGI, Y., "Fermentation Ability of $Z_{y}$ 'momonas mobilis under Various Oxygen Supply Conditions in Batch Culture", Journ. of Ferment. and Bioeng., 69 NO.4, p234-239 (1990).

40. TANAKA, $H$., ISHIKAWA, $H$., and NOBAYASHI, $H$., "Mechanism of Fermentation Performance of Zymomonas mobilis under Oxygen Supply in Batch Culture", Journ. of Fermen. and Bioeng., 20 NO.1, p34-40 (1990).

41. EL-TEMTAMY, S.A., KHALIL,S.A., NOUR-EL-DIN,A A., GABER, A., "Oxygen Mass Transfer in a Bubble Column Bioreactor containg lysed yeast Suspensions", Appl. Microbio. Biotech., 19, p376-381 (1984)

42. THIBAUlT, J., LEDUY, A., and DENIS, A., "Chemical Enhancement in the Determination of $\mathrm{K}_{\mathrm{L}}$ a by the Sulfite Oxidation Method", The Can. Journal of Chem. Eng., 68, p324-326 (1990). 
43. TRAMPER, J., "Immobolizing Biocatalysts for use in Syntheses", Trends in Biotech., 3. p45-50(1985).

44. WANG, D.I.C., JUNKER, B.H., and HATTON, T.A., "Fluorence Sensing of Fermentation Parameters Using Fiber Optics", Biotech. and Bioeng., 32, p55-63 (1990).

45. WANG, D.I.C., JUNKER, B.H., and HATTON, T.A., "Oxygen Transfer Enhancement in Aqueous/Perfluorocarbon Fermentation System: I. Experimental Observations", Biotech. and Bioeng., 35, p578-585 (1990).

46. WANG, D.I.C., JUNKER, B.H., and HATTON, T.A., "Oxygen Transfer Enhancement in Aqueous/Perfluorocarbon Fermentation System: II. Theoretical Analysis", Biolech. and Bioeng., 35, p586-597 (1990).

47. WANG, D.I.C., and McMILlAN, J.D., "Mechanisms of Oxygen Transfer Enhancement during Submerged Cultivation in Perfluorochemical-in-Water Dispersions", Ann. N. Y. Acad. of Sci., 589, p283-300 (1990).

48. WINKLER, M.A., Chemical Engineering Problems in Biotechnology, p215 - 340

49. YOSHIDA, F., YAMANE, T., and MIYAMOTO, Y., "Oxygen Absorption into Oil-inWater Emulsion", Ind. Eng. Chem. Process Des. Develop., 2No.4, p570-578 (1970).

50. YOSHIDA, T., YOKOYAMA, K., CHEN, K.C., SUNOUCHI, T., and TAGUCHI,H., "Oxygen Transfer in Hydrocarbon Fermentation by Candida rugosa", Journ. Ferment. Technol.,55, p76-83 (1977). 